\title{
Electron-Catalyzed Dehydrogenation in a Single-Molecule Junction
}

Hongliang Chen ${ }^{1,2,6, \dagger}$, Feng Jiang ${ }^{3, \dagger}$, Chen $\mathrm{Hu}^{4, \dagger}$, Yang Jiao ${ }^{1}$, Su Chen ${ }^{1}$, Yunyan Qiu ${ }^{1}$, Ping Zhou ${ }^{3}$, Long Zhang ${ }^{1}$, Kang Cai ${ }^{1}$, Bo Song ${ }^{1}$, Xiao-Yang Chen ${ }^{1}$, Xingang Zhao ${ }^{1}$, Michael R.

Wasielewski ${ }^{1}$, Hong Guo ${ }^{4, *}$, Wenjing Hong ${ }^{3, *}$, and J. Fraser Stoddart ${ }^{1,2,5,6, *}$

${ }^{1}$ Department of Chemistry, Northwestern University, 2145 Sheridan Road,

Evanston, Illinois 60208, United States

${ }^{2}$ Stoddart Institute of Molecular Science, Department of Chemistry, Zhejiang University,

Hangzhou 310021, China

${ }^{3}$ State Key Laboratory of Physical Chemistry of Solid Surfaces, iChEM, College of Chemistry and Chemical Engineering, Xiamen University, Xiamen 361005, China

${ }^{4}$ Center for the Physics of Materials and Department of Physics, McGill University, Montreal,

Quebec H3A 2T8, Canada

${ }^{5}$ School of Chemistry, University of New South Wales, Sydney, NSW 2052, Australia

${ }^{6}$ ZJU-Hangzhou Global Scientific and Technological Innovation Center

Hangzhou 311215, China

*E-mail: hong.guo@ mcgill.ca; whong@xmu.edu.cn; stoddart@ northwestern.edu

\section{Supporting Information}

\section{Table of Contents}

Section A. Materials / Methods / Instruments .......................... 2

Section B. Synthetic Protocols ................................................... 3

Section C. NMR Spectroscopy ................................................ 9

Section D. Crystallographic Characterizations ...................... 17

Section E. Supplemental Electrical Measurements ................ 28

Section F. Calculation Methods .............................................. 37

Section G. Supplemental References ..................................... 39 


\section{Section A. Materials / Methods / Instruments}

All reagents were purchased from commercial suppliers and employed without further purification unless stated otherwise. Acetonitrile $(\mathrm{MeCN})$ for reactions was prepared using a solvent drying system. Anhydrous $\mathrm{MeCN}$ for electrolysis and UV-Vis were purchased from Aldrich (anhydrous, 99.8\%). Microwave-assisted reactions were performed on Biotage Microwave Initiator 2.5 with automatic sample loader. Thin layer chromatography (TLC) was performed on silica gel 60 F254 (E. Merck). Column chromatography, including both normal phase (RediSep Rf Gold ${ }^{\circledR}$ NormalPhase Silica) and reversed-phase (RediSep Rf Gold ${ }^{\circledR}$ Reversed-Phase C18), were carried out using CombiFlash $^{\circledR}$ Automation Systems (Teledyne ISCO). UV-Vis Absorption spectra were recorded in a conventional rectangular quartz cell $(10 \times 2 \times 45 \mathrm{~mm})$ on a Shimadzu UV-3600 spectrophotometer in $\mathrm{MeCN}$ at room temperature. Routine nuclear magnetic resonance (NMR) spectra were recorded on Bruker Avance 500 spectrometers, with working frequencies of $500 \mathrm{MHz}$

for ${ }^{1} \mathrm{H}$, and $125 \mathrm{MHz}$ for ${ }^{13} \mathrm{C}$ nuclei, respectively. Chemical shifts are reported in ppm relative to the signals corresponding to the residual nondeuterated solvents $\left(\mathrm{CD}_{3} \mathrm{CN}: \delta_{\mathrm{H}}=1.94 \mathrm{ppm}\right.$ and $\delta_{\mathrm{C}}=$ 1.32 and $118.26 \mathrm{ppm})$. EPR measurements at X-band $(9.5 \mathrm{GHz})$ were performed using a Bruker Elexsys E580, equipped with a 4122SHQE resonator. EPR Samples were prepared by CPE experiments at a reduction potential of $-1.0 \mathrm{~V}$ for $2 \mathrm{~h}$. The solution was transferred into $1.8 \mathrm{~mm}$ o.d. quartz tubes and sealed with a clear ridged UV doming epoxy in an Ar glovebox. Highresolution mass spectra (ESI-HRMS) were measured on a Finnigan LCQ iontrap mass spectrometer. Single-crystal X-ray diffraction (SCXRD) data were collected on a Bruker APEX-II CCD diffractometer. Cyclic voltammetry $(\mathrm{CV})$ was carried out at room temperature in $\mathrm{N}_{2}$-purged $\mathrm{MeCN}$ with a Gamry Multipurpose instrument (Reference 600) interfaced to a computer. CVs on all samples $(0.5 \mathrm{mM}$ in $\mathrm{MeCN})$ were performed using a glassy carbon working electrode $\left(0.071 \mathrm{~cm}^{2}\right)$, a Pt wire counter electrode, and a $\mathrm{Ag} / \mathrm{AgCl}(3 \mathrm{M} \mathrm{NaCl})$ reference electrode. Tetrabutylammonium hexafluorophosphate $\left(\mathrm{TBAPF}_{6}\right)$ of $0.1 \mathrm{M}$ was used as the supporting electrolyte. 


\section{Section B. Synthetic Protocols}

Scheme S1. Structural Formulas and Descriptors for Compounds ${ }^{a, b}$
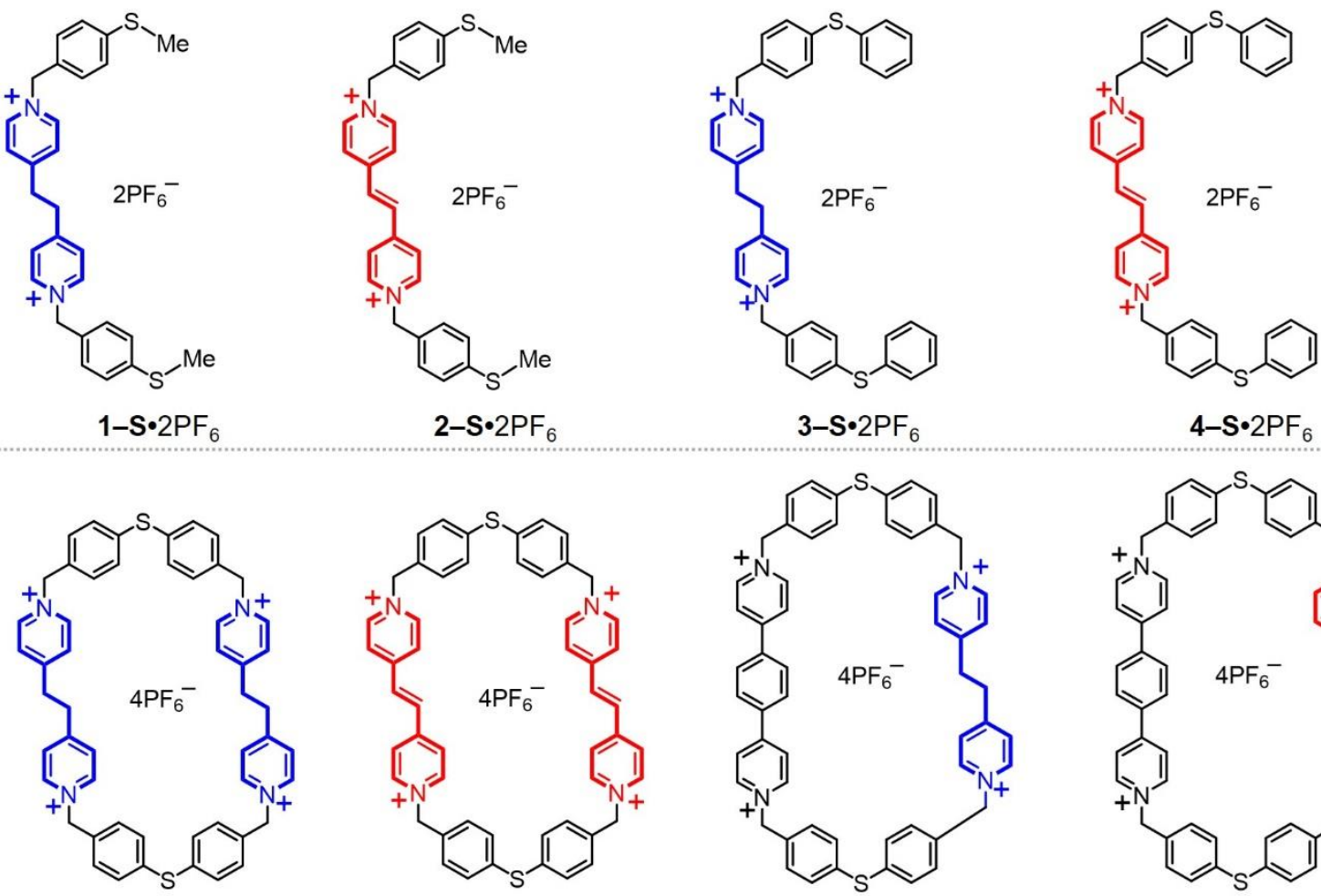

$4-\mathrm{S} \cdot 2 \mathrm{PF}_{6}$

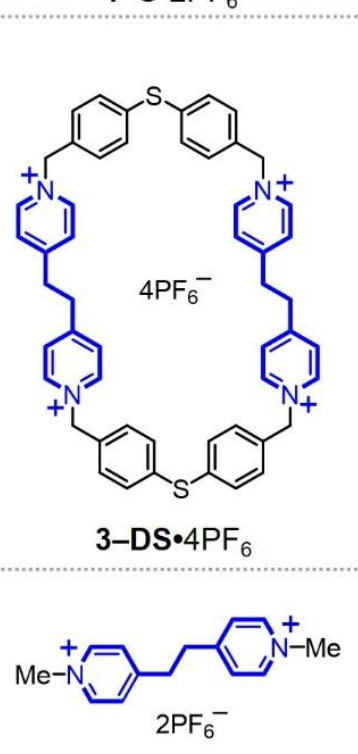

DPA-Me•2PF
4-DS•4PF

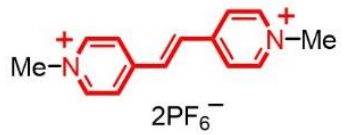

DPE-Me•2PF

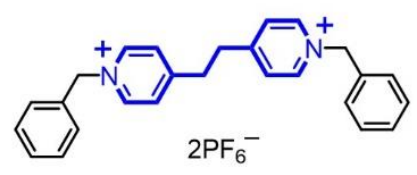

$\mathrm{DPA}-\mathrm{Bn} \cdot 2 \mathrm{PF}_{6}$

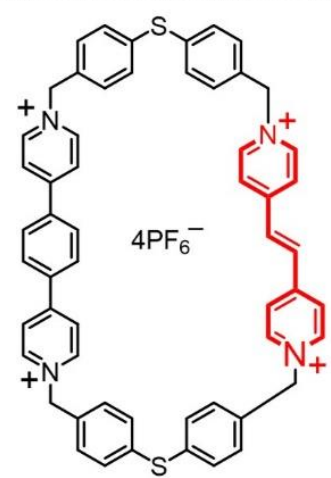

4-DA•4PF 6

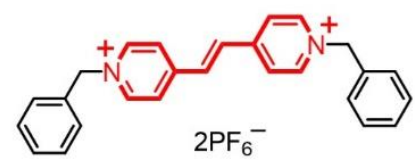

$\mathrm{DPE}-\mathrm{Bn} \cdot 2 \mathrm{PF}_{6}$

a. The preparation and single-molecule conductance measurements of compounds $\mathbf{3}-\mathbf{S} \cdot 2 \mathrm{PF}_{6}, \mathbf{4}$ $\mathbf{S} \bullet 2 \mathrm{PF}_{6}, \mathbf{3}-\mathrm{DS} \bullet 4 \mathrm{PF}_{6}$, and $\mathbf{4}-\mathbf{D S} \bullet 4 \mathrm{PF}_{6}$ have been described in detail in Ref. ${ }^{1}$. Compounds $\mathbf{1}-\mathbf{S} \bullet 2 \mathrm{PF}_{6}$, 2-S•2PF $6,3-\mathbf{D A} \bullet 4 \mathrm{PF}_{6}$, and $\mathbf{4}-\mathbf{D A} \bullet 4 \mathrm{PF}_{6}$ are newly designed compounds incorporating $\mathrm{DPA}^{2+}$ (marked in blue) or $\mathrm{DPE}^{2+}$ (marked in red) backbones.

b. Compounds DPA-Me $2 \mathrm{PF}_{6}, \quad \mathrm{DPE}-\mathrm{Me} \cdot 2 \mathrm{PF}_{6}, \mathrm{DPA}-\mathbf{B n} \cdot 2 \mathrm{PF}_{6}$, and $\mathrm{DPE}-\mathbf{B n} \cdot 2 \mathrm{PF}_{6}$ were synthesized in order to investigate of dehydrogenation mechanism in ensemble experiments. 


\section{(1) Synthesis of Dimethyl Extend Viologens}

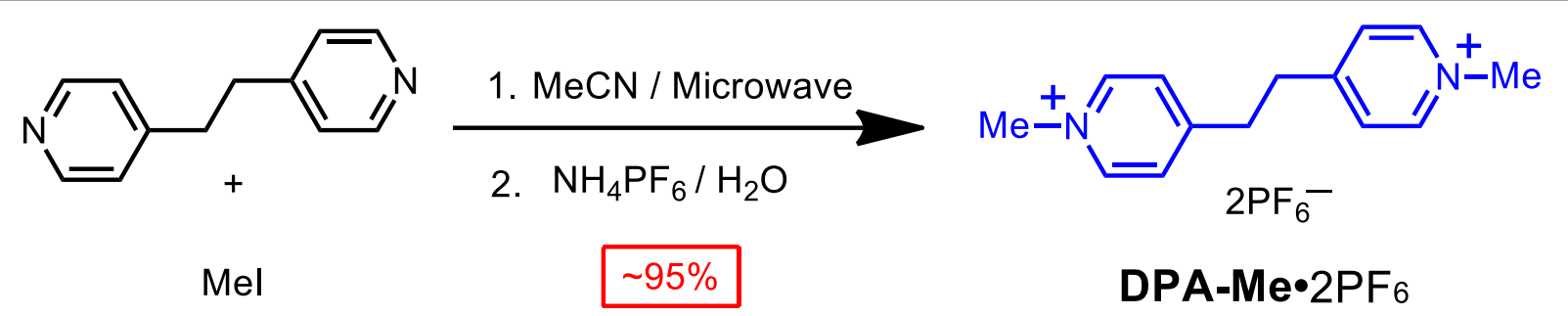

Scheme S2. Synthesis of DPA-Me $2 \mathrm{PF}_{6}$.

DPA-Me•2PF 6: An MeCN (5 mL) solution of 1,2-di(pyridin-4-yl)ethane (200 mg) and excess of MeI ( $\sim 10$ equiv) were introduced into a microwave vial. The reaction mixture was irradiated in a microwave at $100{ }^{\circ} \mathrm{C}, 50 \mathrm{~W}$ for $30 \mathrm{~min}$. After the reaction mixture had cooled to ambient temperature, the precipitate was filtered off and the unreacted MeI was removed with multiple $\mathrm{Et}_{2} \mathrm{O}$ washings to obtain the pure DPA-Me•2I. Finally, DPA-Me•2I was dissolved in $\mathrm{H}_{2} \mathrm{O}(\sim 20 \mathrm{~mL})$ and DPA-Me $2 \mathrm{PF}_{6}$ was reprecipitated by adding solid $\mathrm{NH}_{4} \mathrm{PF}_{6}$ salt, and collected by filtration. Excess of $\mathrm{NH}_{4} \mathrm{PF}_{6}$ was removed by washing several times with $\mathrm{MeOH}$ and $\mathrm{Et}_{2} \mathrm{O}$ to obtain DPA-Me $2 \mathrm{PF}_{6}$ as a pure white solid. in $\sim 95 \%$ yield. ${ }^{1} \mathrm{H}$ NMR (500 MHz, $\left.\mathrm{CD}_{3} \mathrm{CN}, \mathrm{ppm}\right): \delta=8.49$ (d, $J=6.6 \mathrm{~Hz}$, 4H), $7.82(\mathrm{~d}, J=6.6 \mathrm{~Hz}, 4 \mathrm{H}), 4.24$ (s, 6H), 3.28 (s, 4H). ${ }^{13} \mathrm{C} \mathrm{NMR}\left(125 \mathrm{MHz}, \mathrm{CD}_{3} \mathrm{CN}, \mathrm{ppm}\right): \delta=$ $161.1,145.8,128.8,48.7,35.1$.

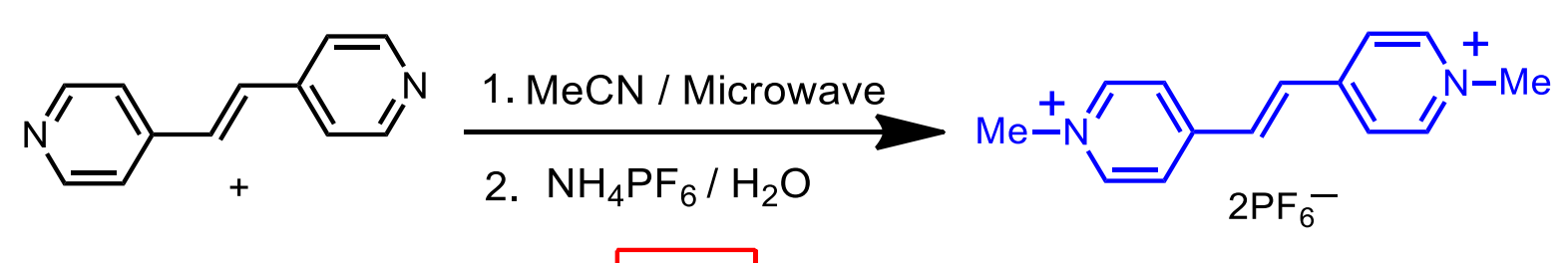

Mel $\sim 95 \%$ DPE-Me•2PF6

Scheme S3. Synthesis of DPE-Me• $2 \mathrm{PF}_{6}$.

DPE-Me•2PF6: This compound was prepared using the same methodology as used in the preparation of DPA-Me $2 \mathrm{PF}_{6}$. DPE-Me• $2 \mathrm{PF}_{6}$ was isolated as a white solid with a yield in $\sim 95 \%$. 
${ }^{1} \mathrm{H}$ NMR $\left(500 \mathrm{MHz}, \mathrm{CD}_{3} \mathrm{CN}, \mathrm{ppm}\right): \delta=8.62(\mathrm{~d}, J=6.9 \mathrm{~Hz}, 4 \mathrm{H}), 8.14(\mathrm{~d}, J=6.9 \mathrm{~Hz}, 4 \mathrm{H}), 7.81(\mathrm{~s}$, 2H), $4.29(\mathrm{~s}, 6 \mathrm{H}) .{ }^{13} \mathrm{C} \mathrm{NMR}\left(125 \mathrm{MHz}, \mathrm{CD}_{3} \mathrm{CN}, \mathrm{ppm}\right): \delta=151.8,146.6,134.7,126.5,48.9$.

\section{(2) Synthesis of Single-Channel Compounds}

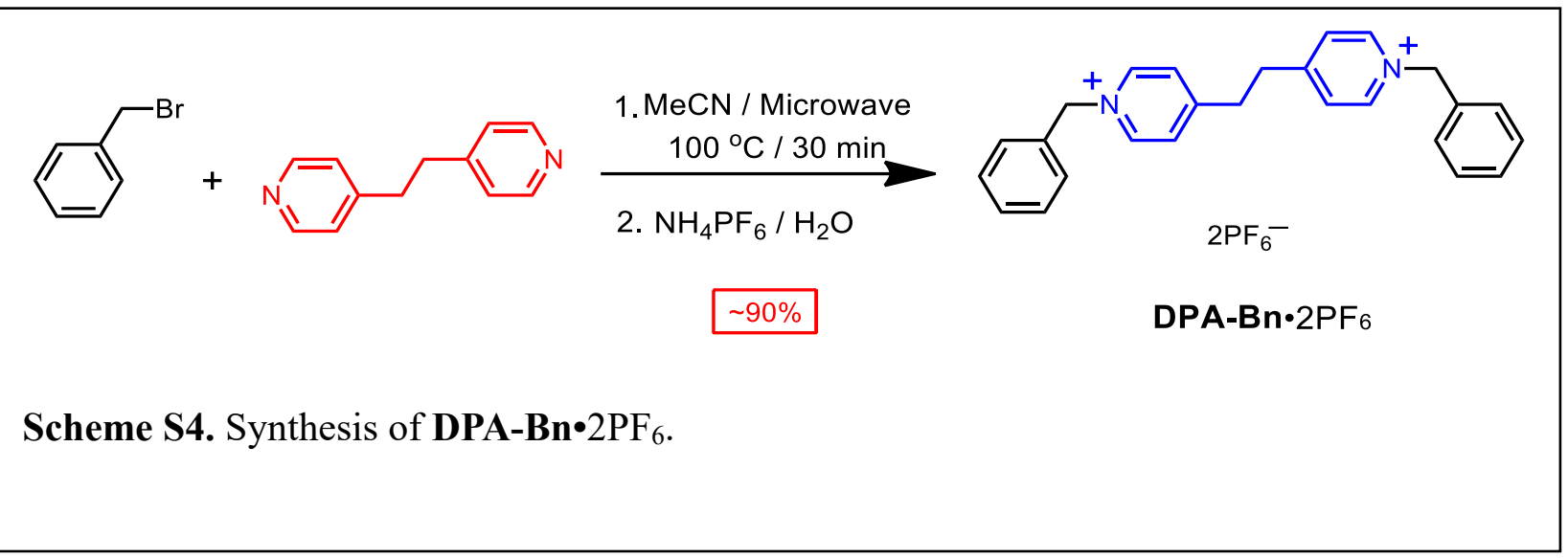

DPA-Bn•2PF6: An MeCN (5 mL) solution of 1,2-di(pyridin-4-yl)ethane (200 mg) and excess of benzyl bromide ( $\sim 8$ equiv) were introduced into a microwave vial. The reaction mixture was irradiated in a microwave at $100{ }^{\circ} \mathrm{C}$ and $50 \mathrm{~W}$ for $30 \mathrm{~min}$. After the reaction mixture had cooled to ambient temperature, the precipitate was filtered off and the unreacted benzyl bromide was removed with multiple $\mathrm{Et}_{2} \mathrm{O}$ washings to obtain the pure DPA-Bn・2Br. Finally, DPA-Bn・2Br was dissolved in $\mathrm{H}_{2} \mathrm{O}(\sim 20 \mathrm{~mL})$ and DPA-Bn・2PF 6 was reprecipitated by adding solid $\mathrm{NH}_{4} \mathrm{PF}_{6}$ salt, and collected by filtration. Excess of $\mathrm{NH}_{4} \mathrm{PF}_{6}$ was removed by washing several times with $\mathrm{MeOH}$ and $\mathrm{Et}_{2} \mathrm{O}$ to obtain DPA-Bn・2PF 6 as a pure white solid with a yield in $\sim 90 \%$. ${ }^{1} \mathrm{H} \mathrm{NMR}(500 \mathrm{MHz}$, $\left.\mathrm{CD}_{3} \mathrm{CN}, \mathrm{ppm}\right): \delta=8.62(\mathrm{~d}, J=6.9 \mathrm{~Hz}, 4 \mathrm{H}), 7.87(\mathrm{~d}, J=6.9 \mathrm{~Hz}, 4 \mathrm{H}), 7.49-7.41(\mathrm{~m}, 10 \mathrm{H}), 5.66(\mathrm{~s}$, 4H), 3.27 (s, 4H). ${ }^{13} \mathrm{C}$ NMR (125 MHz, $\left.\mathrm{CD}_{3} \mathrm{CN}, \mathrm{ppm}\right): \delta=162.0,144.9,133.9,130.8,130.4,130.0$, 129.3, 64.8, 35.1. HRMS-ESI for DPA-Bn•2PF ; Calcd for $\mathrm{C}_{26} \mathrm{H}_{26} \mathrm{~F}_{12} \mathrm{~N}_{2} \mathrm{P}_{2}: m / z=551.1738[M-$ $\left.\mathrm{PF}_{6}\right]^{+}$; Found $551.1745\left[M-\mathrm{PF}_{6}\right]^{+}$. 


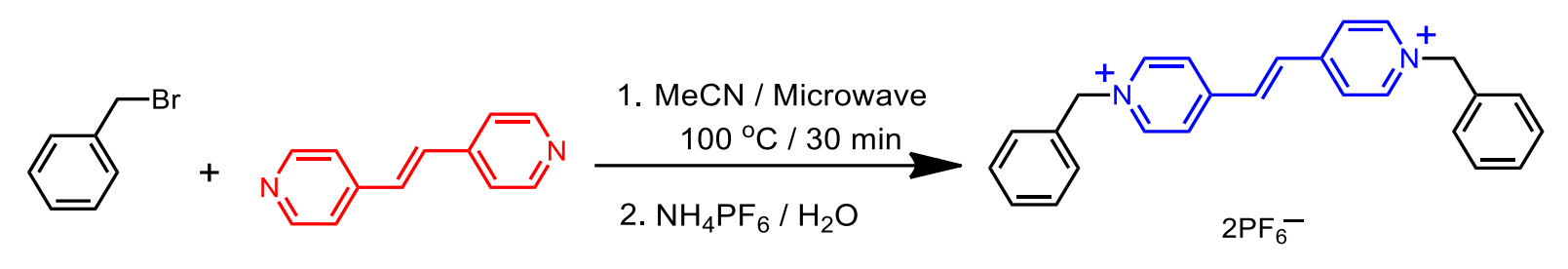

$\sim 90 \%$

DPE-Bn·2PF 6

Scheme S5. Synthesis of DPE-Bn•2PF6.

DPE-Bn•2PF6: This compound was prepared using the same synthetic methodology as for DPA-

Bn·2PF 6 DPE-Bn•2PF 6 was obtained as a yellow solid with a yield of $\sim 90 \%$. ${ }^{1} \mathrm{H}$ NMR $(500 \mathrm{MHz}$, $\left.\mathrm{CD}_{3} \mathrm{CN}, \mathrm{ppm}\right): \delta=8.73(\mathrm{~d}, J=6.9 \mathrm{~Hz}, 4 \mathrm{H}), 8.15(\mathrm{~d}, J=6.9 \mathrm{~Hz}, 4 \mathrm{H}), 7.81(\mathrm{~s}, 2 \mathrm{H}), 7.49-7.47(\mathrm{~m}$, 10H), $5.70(\mathrm{~s}, 4 \mathrm{H}) .{ }^{13} \mathrm{C} \mathrm{NMR}\left(125 \mathrm{MHz}, \mathrm{CD}_{3} \mathrm{CN}, \mathrm{ppm}\right): \delta=152.4,145.7,135.0,133.8,130.9$, 130.5, 130.1, 127.1, 65.0. HRMS-ESI for DPE-Bn•2PF ; Calcd for $\mathrm{C}_{26} \mathrm{H}_{24} \mathrm{~F}_{12} \mathrm{~N}_{2} \mathrm{P}_{2}: \mathrm{m} / z=509.1581$ $\left[M-\mathrm{PF}_{6}\right]^{+} ;$Found $509.1565\left[M-\mathrm{PF}_{6}\right]^{+}$.

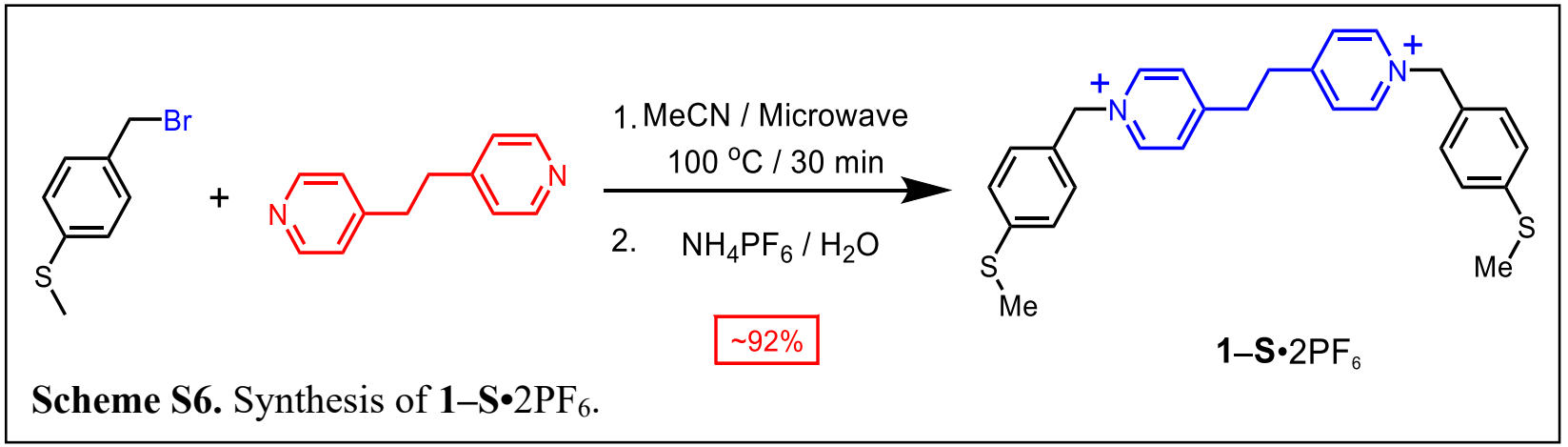

1-S•2PF6: This compound was prepared using the same synthetic methodology as for DPABn・2PF $6 . \mathbf{1}-\mathbf{S} \cdot 2 \mathrm{PF}_{6}$ was and obtained as a yellow solid with a yield of $\sim 92 \%$ yield. ${ }^{1} \mathrm{H}$ NMR (500 $\left.\mathrm{MHz}, \mathrm{CD}_{3} \mathrm{CN}, \mathrm{ppm}\right): \delta=8.60(\mathrm{~d}, J=6.9 \mathrm{~Hz}, 4 \mathrm{H}), 7.85(\mathrm{~d}, J=6.9 \mathrm{~Hz}, 4 \mathrm{H}), 7.36-7.32(\mathrm{~m}, 8 \mathrm{H})$, $5.60(\mathrm{~s}, 4 \mathrm{H}), 3.26(\mathrm{~s}, 4 \mathrm{H}), 2.49(\mathrm{~s}, 6 \mathrm{H}) .{ }^{13} \mathrm{C} \mathrm{NMR}\left(125 \mathrm{MHz}, \mathrm{CD}_{3} \mathrm{CN}, \mathrm{ppm}\right): \delta=162.0,144.8$, 142.4, 130.7, 130.0, 129.3, 127.3, 64.4, 35.1, 15.1. HRMS-ESI for 1-S•2PF ; Calcd for $\mathrm{C}_{28} \mathrm{H}_{30} \mathrm{~F}_{12} \mathrm{~N}_{2} \mathrm{P}_{2} \mathrm{~S}_{2}: m / z=603.1492\left[M-\mathrm{PF}_{6}\right]^{+}$; Found $603.1502\left[M-\mathrm{PF}_{6}\right]^{+}$. 


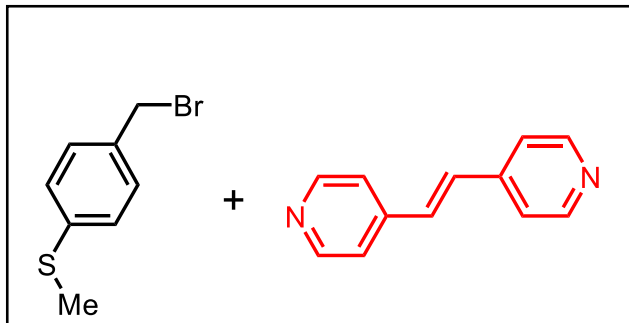

Scheme S7. Synthesis of $2-\mathrm{S} \cdot 2 \mathrm{PF}_{6}$.
1. MeCN / Microwave $100^{\circ} \mathrm{C} / 30 \mathrm{~min}$

2. $\mathrm{NH}_{4} \mathrm{PF}_{6} / \mathrm{H}_{2} \mathrm{O}$

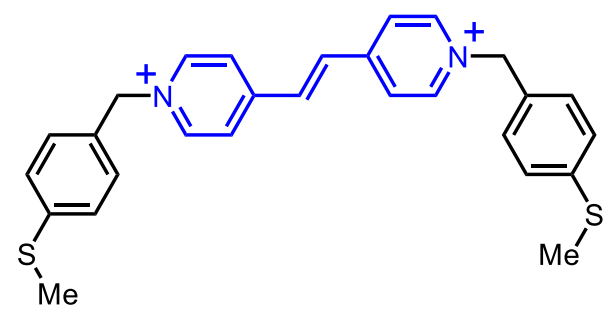

$\mathbf{2}-\mathbf{S} \cdot 2 \mathrm{PF}{ }_{6}$

2-S•2PF6: This compound was prepared using the same synthetic methodology as for DPA$\mathbf{B n} \cdot 2 \mathrm{PF}_{6} .2-\mathbf{S} \cdot 2 \mathrm{PF}_{6}$ was obtained as a yellow solid with a yield of $\sim 90 \%$ yield. ${ }^{1} \mathrm{H} \mathrm{NMR}(500 \mathrm{MHz}$, $\left.\mathrm{CD}_{3} \mathrm{CN}, \mathrm{ppm}\right): \delta=8.71(\mathrm{~d}, J=6.9 \mathrm{~Hz}, 4 \mathrm{H}), 8.13(\mathrm{~d}, J=6.9 \mathrm{~Hz}, 4 \mathrm{H}), 7.79(\mathrm{~s}, 4 \mathrm{H}), 7.40-7.34(\mathrm{~m}$, $8 \mathrm{H}), 5.64$ (s, 4H), 2.49 (s, 6H). ${ }^{13} \mathrm{C}$ NMR (125 MHz, $\left.\mathrm{CD}_{3} \mathrm{CN}, \mathrm{ppm}\right): \delta=152.4,145.6,142.6,134.9$, 130.8, 129.8, 127.3, 127.0, 64.6, 15.1. HRMS-ESI for $2-\mathrm{S} \cdot 2 \mathrm{PF}_{6}$; Calcd for $\mathrm{C}_{28} \mathrm{H}_{28} \mathrm{~F}_{12} \mathrm{~N}_{2} \mathrm{P}_{2} \mathrm{~S}_{2}: m / z$ $=601.1336\left[M-\mathrm{PF}_{6}\right]^{+} ;$Found $601.1334\left[M-\mathrm{PF}_{6}\right]^{+}$.

\section{(3) Synthesis of Double-Channel Asymmetric Charged Cyclophanes}

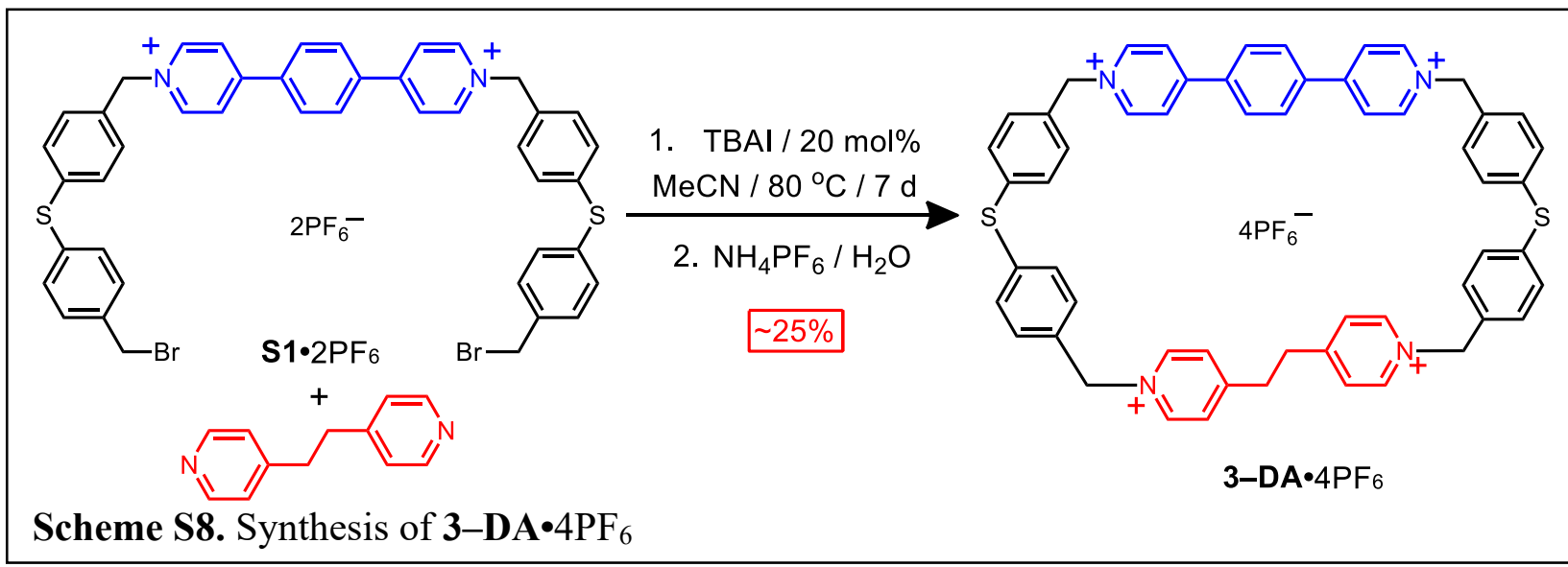

3-DA•4PF6: The starting materials $\mathbf{S 1} \cdot 2 \mathrm{PF}_{6}$ (1 euqiv, $200 \mathrm{mg}, 0.18 \mathrm{mmol}$ ), 1,2-di(pyridin-4yl)ethane (1 euqiv, $33.4 \mathrm{mg}, 0.18 \mathrm{mmol})$ and TBAI (20 mol\%, $13.4 \mathrm{mg}, 0.036 \mathrm{mmol})$ were introduced into round-bottomed flask and dry $\mathrm{MeCN}(100 \mathrm{~mL})$ was added to the flask. The mixture was stirred at $80{ }^{\circ} \mathrm{C}$ for 7 days. The reaction mixture was cooled to room temperature and excess of tetrabutylammonium chloride (TBACl) was added to quench the reaction. The resulting crude precipitate was then subjected to reverse-phase $\mathrm{C}_{18}$ column chromatography, starting with $\mathrm{H}_{2} \mathrm{O}$ / 
$0.1 \%$ TFA as eluent and ending up with an eluent mixture of $99.9 \% \mathrm{MeCN} / 0.1 \%$ TFA over the course of $45 \mathrm{~min}$. The pure fractions were collected and $\mathrm{MeCN}$ was removed by rotary evaporation under vacuum. Finally, $\mathrm{NH}_{4} \mathrm{PF}_{6}$ was added to precipitate the pure product which was then separated by filtration. The excess of $\mathrm{NH}_{4} \mathrm{PF}_{6}$ was removed by washing several times with $\mathrm{H}_{2} \mathrm{O}$ to obtain the pure white solid of $\mathbf{3}-\mathbf{D A} \cdot 4 \mathrm{PF}_{6}$ in $25 \%$ yield. ${ }^{1} \mathrm{H} \mathrm{NMR}\left(500 \mathrm{MHz}, \mathrm{CD}_{3} \mathrm{CN}, \mathrm{ppm}\right): \delta=8.78(\mathrm{~d}, J=$ $6.9 \mathrm{~Hz}, 4 \mathrm{H}), 8.57(\mathrm{~d}, J=6.9 \mathrm{~Hz}, 4 \mathrm{H}), 8.32(\mathrm{~d}, J=5.4 \mathrm{~Hz}, 4 \mathrm{H}), 8.09$ (s, 4H), 7.87 (d, $J=5.4 \mathrm{~Hz}$, 4H), 7.47-7.29 (m, 16H), $5.75(\mathrm{~s}, 4 \mathrm{H}), 5.63(\mathrm{~s}, 4 \mathrm{H}), 3.15(\mathrm{~s}, 4 \mathrm{H}) .{ }^{13} \mathrm{C} \mathrm{NMR}\left(125 \mathrm{MHz}, \mathrm{CD}_{3} \mathrm{CN}\right.$, ppm): $\delta=162.3,156.2,145.7,145.1,138.4,137.9,137.1,134.3,133.4,132.9,131.9,130.8,130.6$, 130.3, 129.2, 126.8, 64.3, 64.1, 35.2. HRMS-ESI for 3-DA•4PF ; Calcd for $\mathrm{C}_{56} \mathrm{H}_{48} \mathrm{~F}_{24} \mathrm{~N}_{4} \mathrm{P}_{4} \mathrm{~S}_{2}: m / z$ $=1275.2246\left[M-\mathrm{PF}_{6}\right]^{2+} ;$ Found $1275.2261\left[M-\mathrm{PF}_{6}\right]^{+}$.

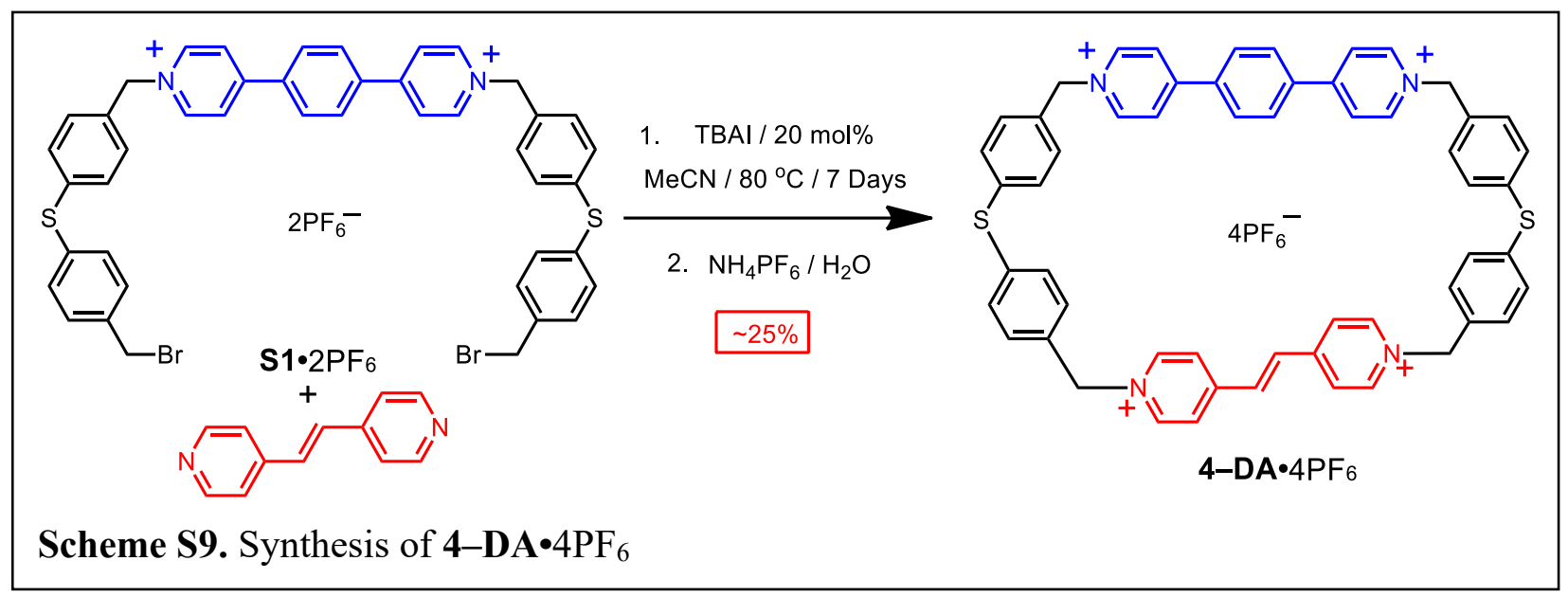

4-DA-4PF6: This compound was prepared using the same synthetic methodology as for 3DA•4PF $6.4-\mathbf{D A} \cdot 4 \mathrm{PF}_{6}$ was obtained as a yellow solid with a yield of $\sim 15 \%$ yield. ${ }^{1} \mathrm{H}$ NMR (500 $\left.\mathrm{MHz}, \mathrm{CD}_{3} \mathrm{CN}, \mathrm{ppm}\right): \delta=8.77(\mathrm{~d}, J=6.9 \mathrm{~Hz}, 4 \mathrm{H}), 8.64(\mathrm{~d}, J=6.9 \mathrm{~Hz}, 4 \mathrm{H}), 8.30(\mathrm{~d}, J=5.4 \mathrm{~Hz}$, 4H), $8.30(\mathrm{~d}, J=5.4 \mathrm{~Hz}, 4 \mathrm{H}), 8.07(\mathrm{~s}, 4 \mathrm{H}), 7.73(\mathrm{~s}, 2 \mathrm{H}), 7.48-7.31(\mathrm{~m}, 16 \mathrm{H}), 5.74(\mathrm{~s}, 4 \mathrm{H}), 5.67$ (s, 4H). ${ }^{13} \mathrm{C}$ NMR (125 MHz, $\left.\mathrm{CD}_{3} \mathrm{CN}, \mathrm{ppm}\right): \delta=145.9,145.8,138.4,137.9,134.9,134.2,133.3(3)$, 133.3(1), 132.7, 132.0, 130.9(1), 130.89, 130.7, 130.6, 130.3, 127.0, 126.8, 64.3, 64.2. HRMS-ESI for 4-DA•4PF 6 ; Calcd for $\mathrm{C}_{56} \mathrm{H}_{46} \mathrm{~F}_{24} \mathrm{~N}_{4} \mathrm{P}_{4} \mathrm{~S}_{2}: m / z=1273.2089\left[M-\mathrm{PF}_{6}\right]^{+}$; Found $1273.2067[M-$ $\left.\mathrm{PF}_{6}\right]^{+}$. 


\section{Section C. NMR Spectroscopy}

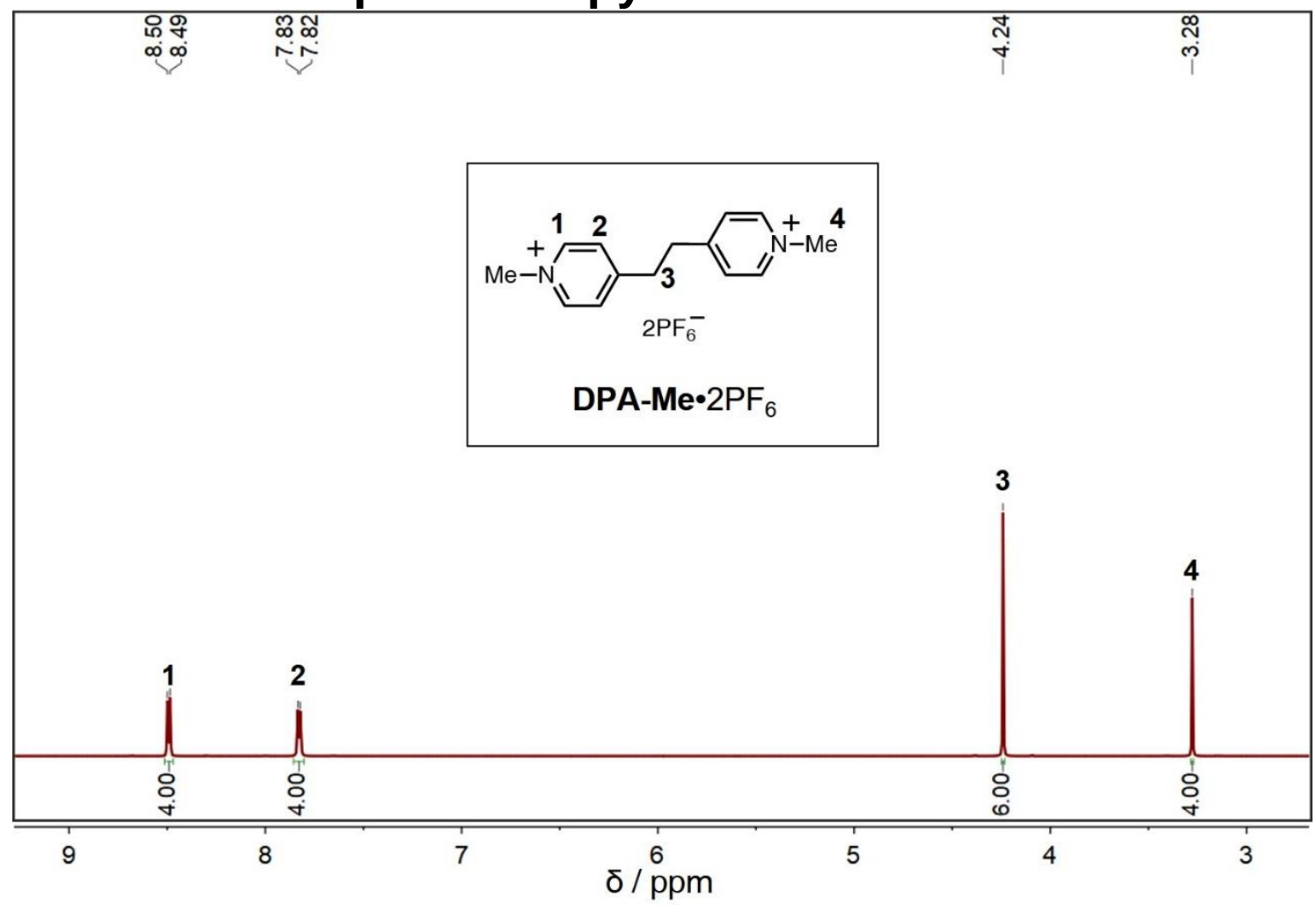

Figure S1. ${ }^{1} \mathrm{H}$ NMR spectrum $\left(500 \mathrm{MHz}, \mathrm{CD}_{3} \mathrm{CN}, 298 \mathrm{~K}\right)$ of DPA-Me•2PF 6

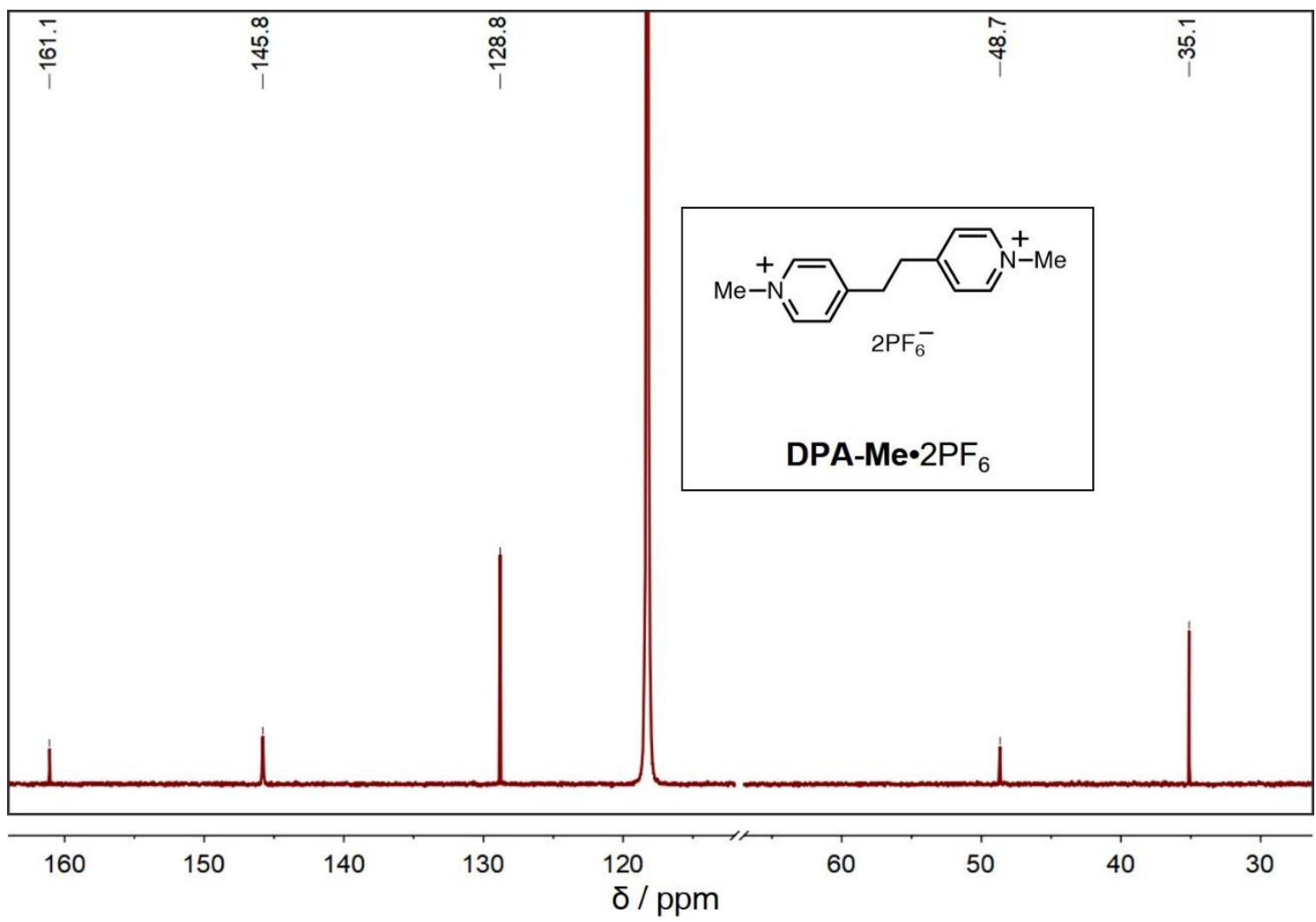

Figure S2. ${ }^{13} \mathrm{C}$ NMR spectrum $\left(125 \mathrm{MHz}, \mathrm{CD}_{3} \mathrm{CN}, 298 \mathrm{~K}\right)$ of DPA-Me•2PF 6 


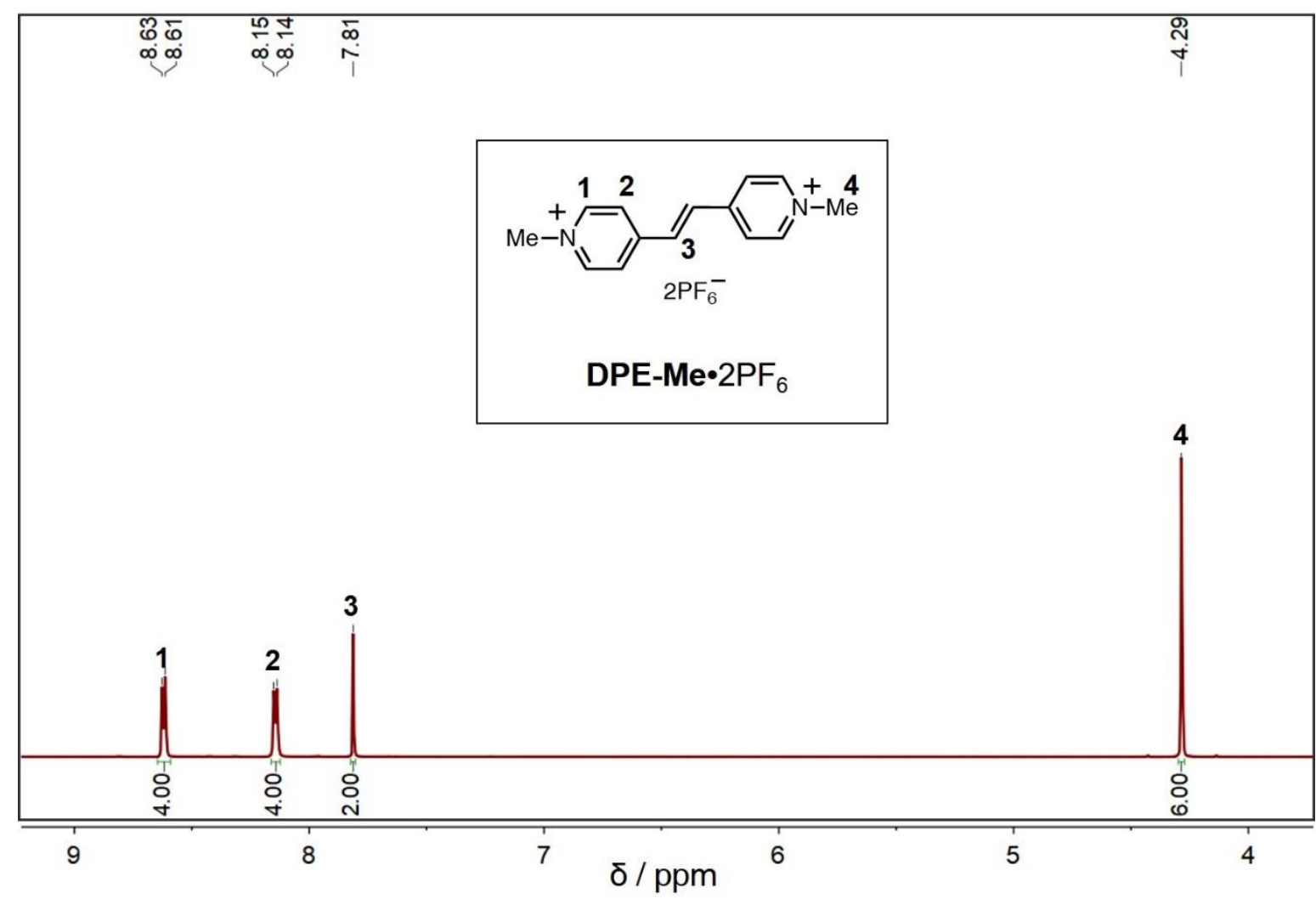

Figure S3. ${ }^{1} \mathrm{H}$ NMR spectrum $\left(500 \mathrm{MHz}, \mathrm{CD}_{3} \mathrm{CN}, 298 \mathrm{~K}\right)$ of DPE-Me•2PF6

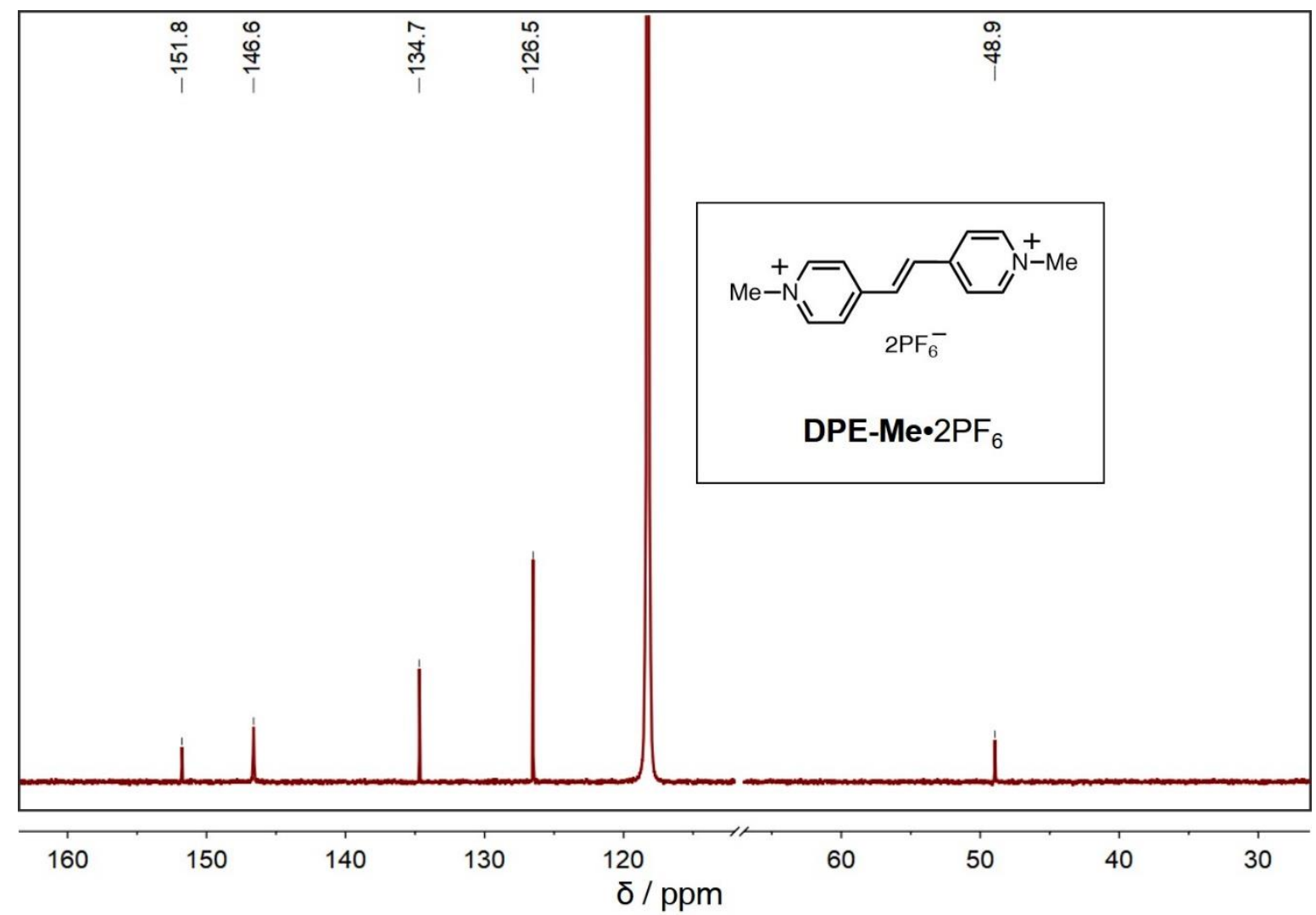

Figure S4. ${ }^{13} \mathrm{C}$ NMR spectrum $\left(125 \mathrm{MHz}, \mathrm{CD}_{3} \mathrm{CN}, 298 \mathrm{~K}\right)$ of $\mathbf{D P E}-\mathbf{M e} \cdot 2 \mathrm{PF}_{6}$ 


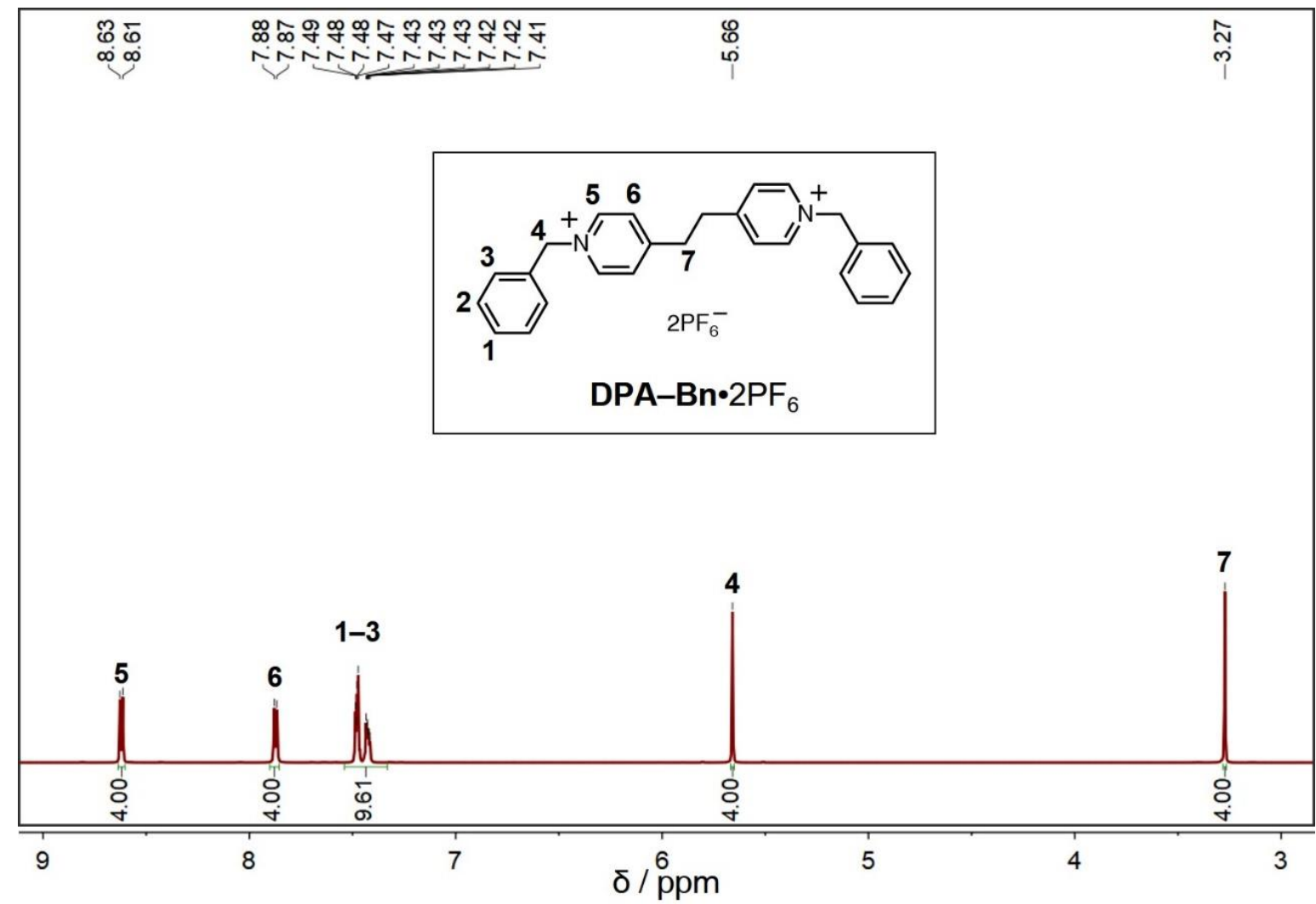

Figure S5. ${ }^{1} \mathrm{H}$ NMR spectrum $\left(500 \mathrm{MHz}, \mathrm{CD}_{3} \mathrm{CN}, 298 \mathrm{~K}\right)$ of DPA-Bn•2PF 6

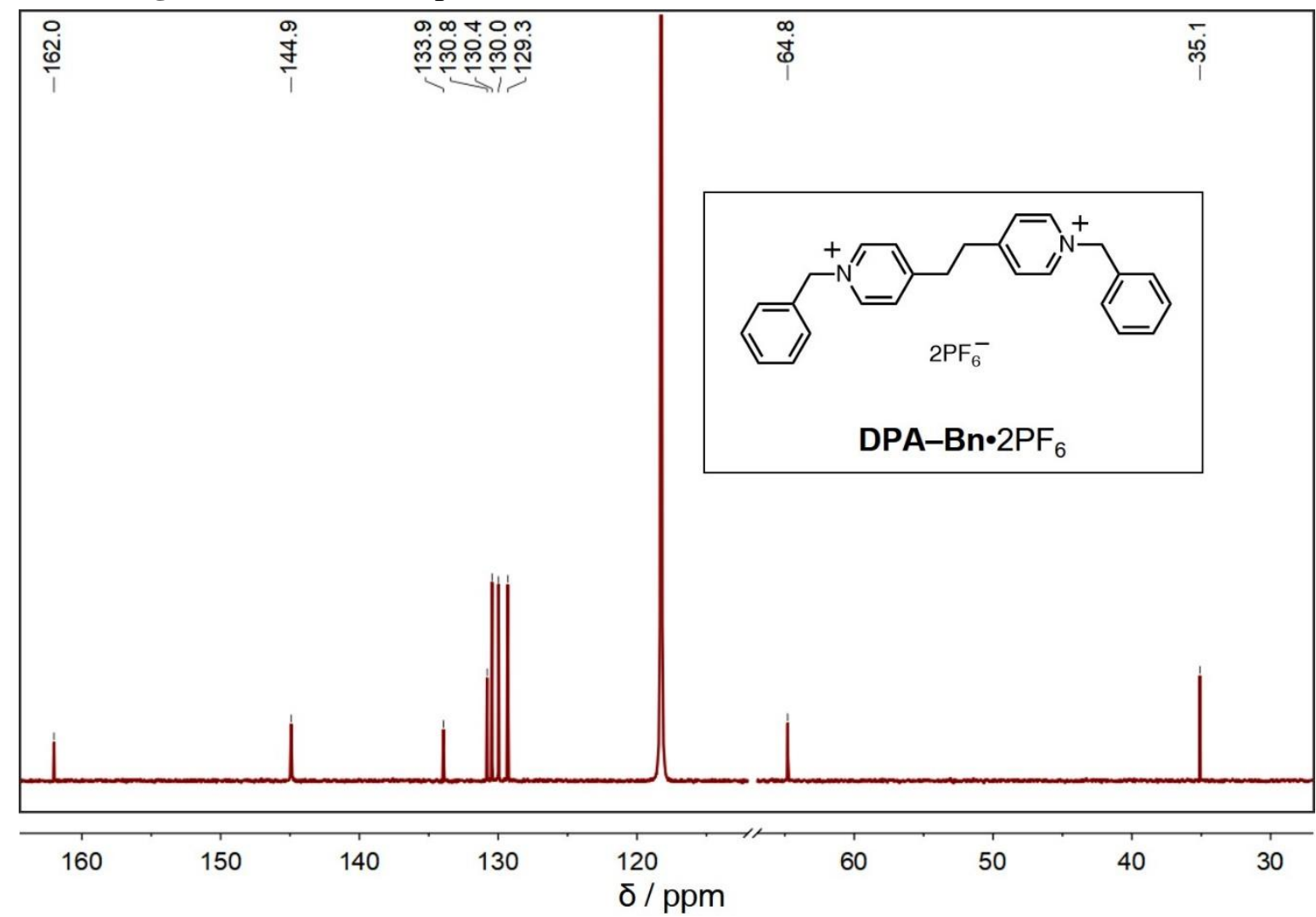

Figure S6. ${ }^{13} \mathrm{C}$ NMR spectrum $\left(125 \mathrm{MHz}, \mathrm{CD}_{3} \mathrm{CN}, 298 \mathrm{~K}\right)$ of DPA-Bn・2PF 6 


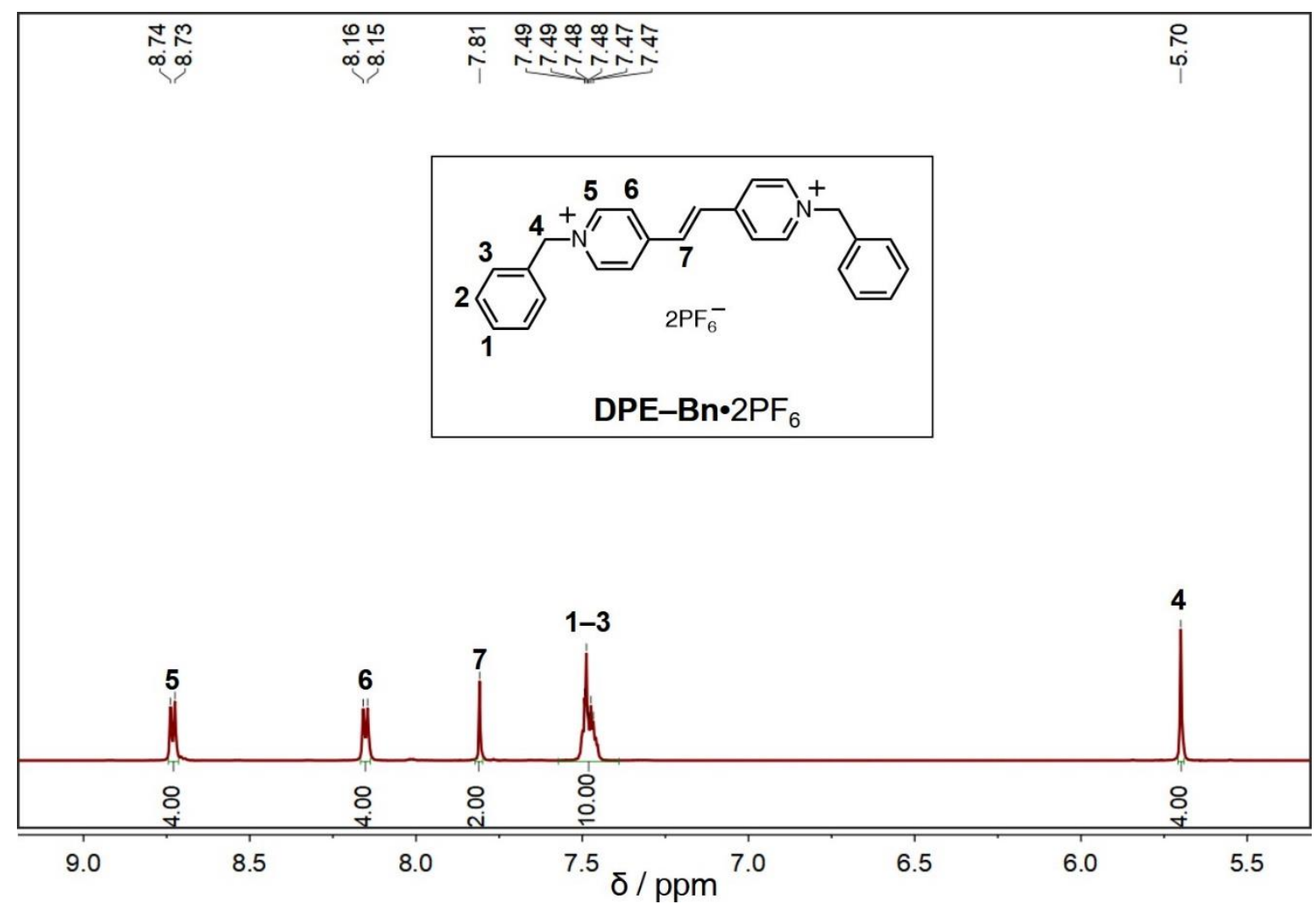

Figure S7. ${ }^{1} \mathrm{H}$ NMR spectrum $\left(500 \mathrm{MHz}, \mathrm{CD}_{3} \mathrm{CN}, 298 \mathrm{~K}\right)$ of DPE-Bn•2PF 6

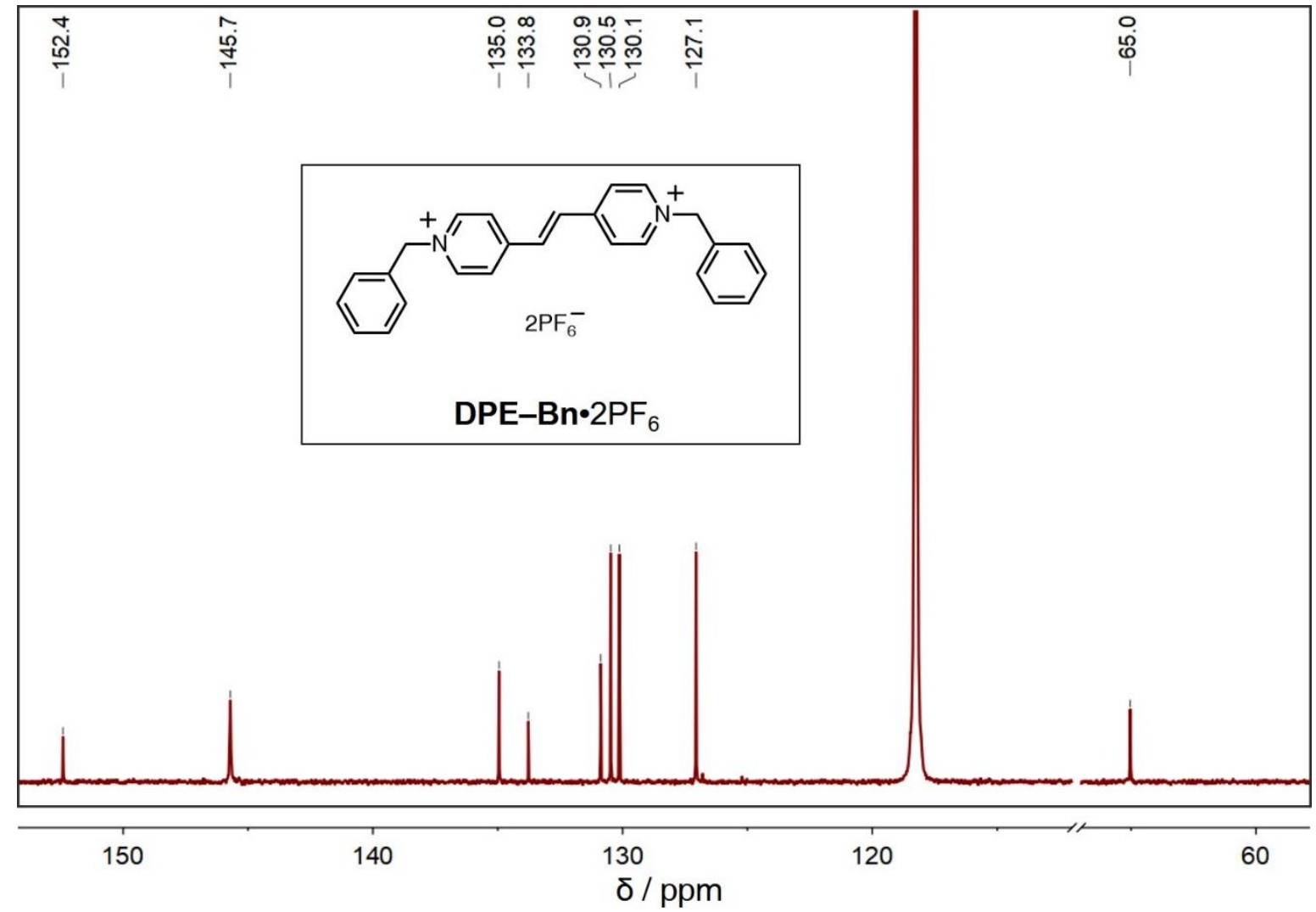

Figure S8. ${ }^{13} \mathrm{C}$ NMR spectrum $\left(125 \mathrm{MHz}, \mathrm{CD}_{3} \mathrm{CN}, 298 \mathrm{~K}\right)$ of DPE$-\mathbf{B n} \cdot 2 \mathrm{PF}_{6}$ 


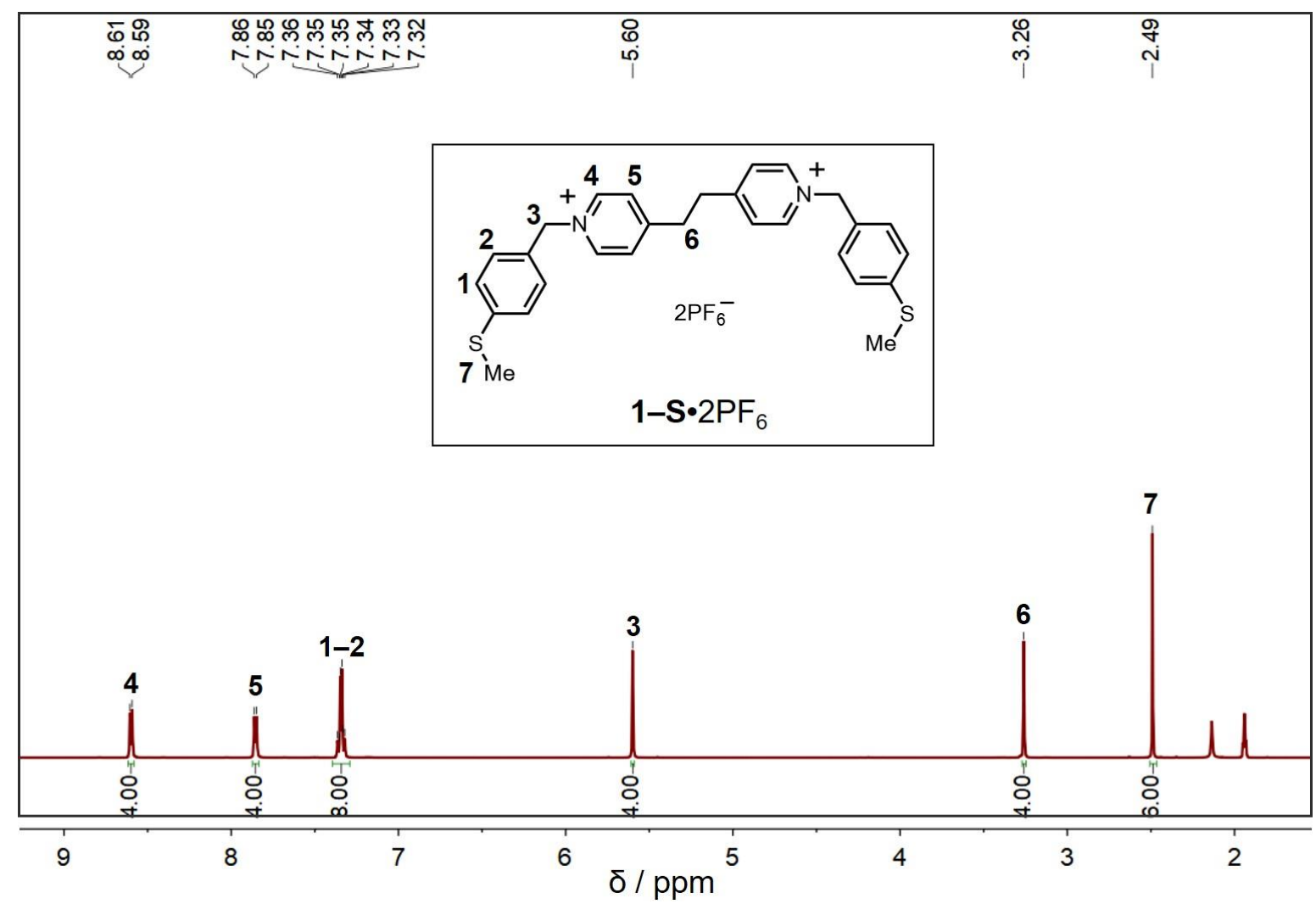

Figure S9. ${ }^{1} \mathrm{H}$ NMR spectrum $\left(500 \mathrm{MHz}, \mathrm{CD}_{3} \mathrm{CN}, 298 \mathrm{~K}\right)$ of $\mathbf{1}-\mathbf{S} \cdot 2 \mathrm{PF}_{6}$

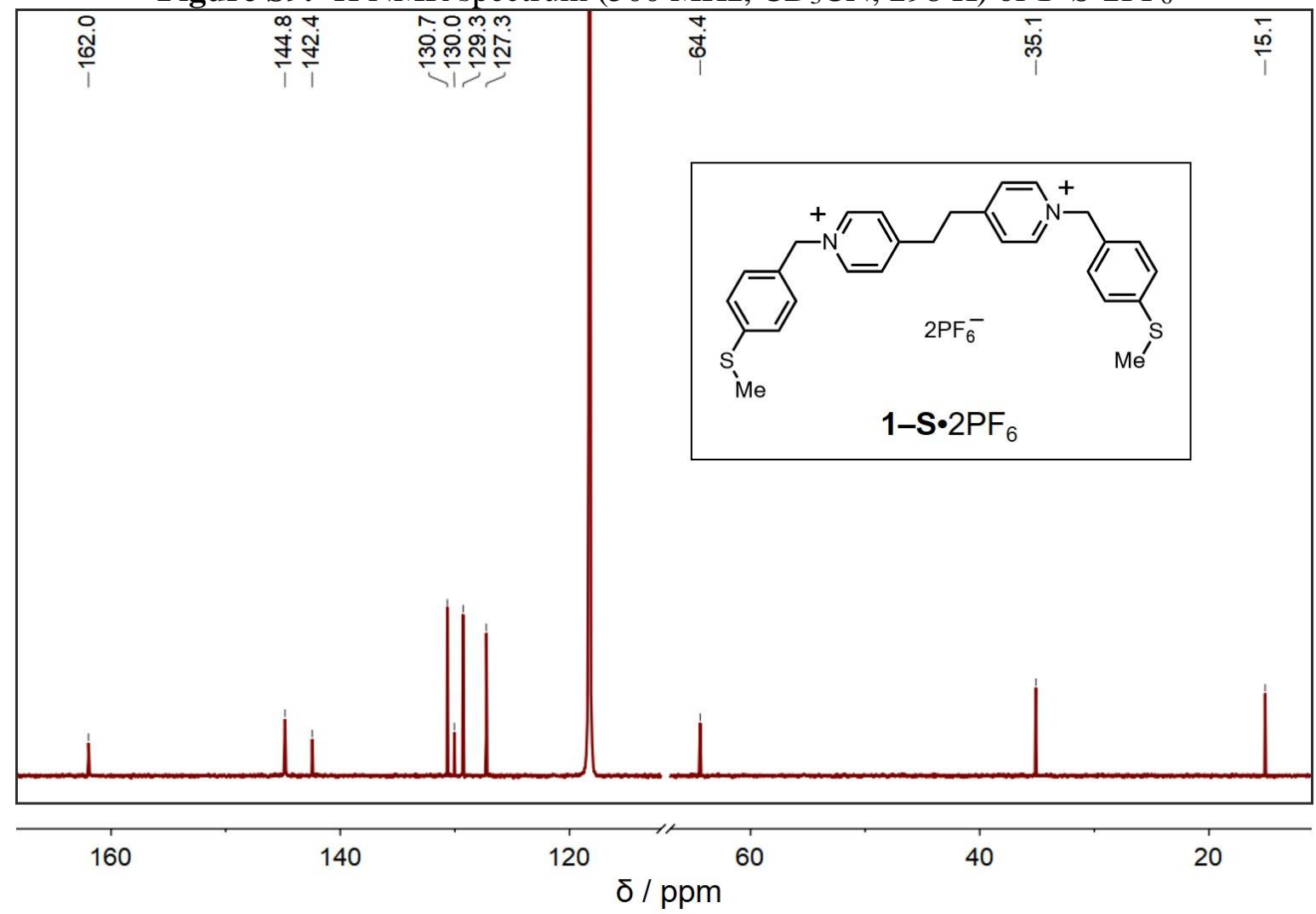

Figure S10. ${ }^{13} \mathrm{C}$ NMR spectrum $\left(125 \mathrm{MHz}, \mathrm{CD}_{3} \mathrm{CN}, 298 \mathrm{~K}\right)$ of $\mathbf{1}-\mathbf{S} \cdot 2 \mathrm{PF}_{6}$ 


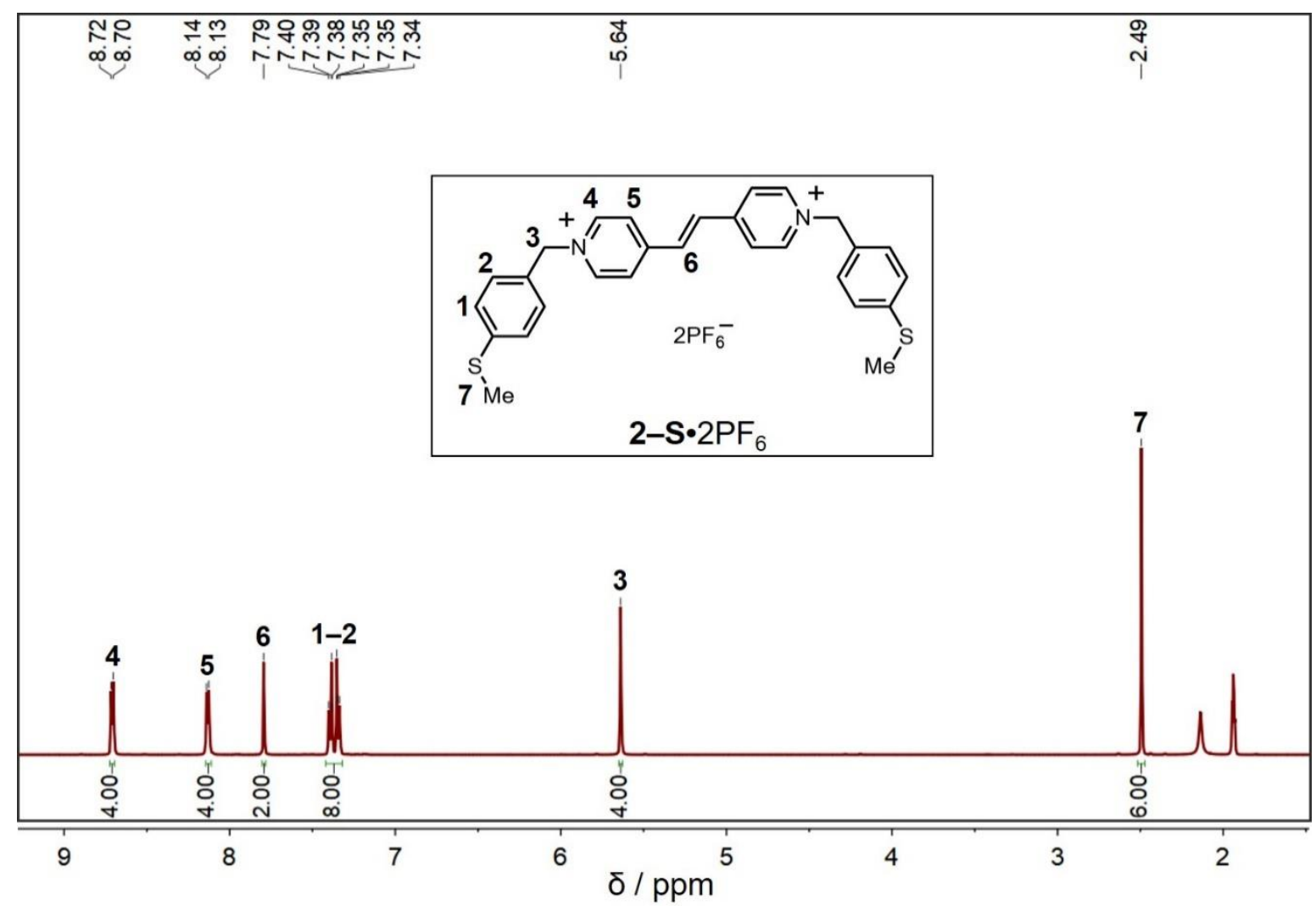

Figure S11. ${ }^{1} \mathrm{H}$ NMR spectrum $\left(500 \mathrm{MHz}, \mathrm{CD}_{3} \mathrm{CN}, 298 \mathrm{~K}\right)$ of $\mathbf{2}-\mathbf{S} \cdot 2 \mathrm{PF}_{6}$

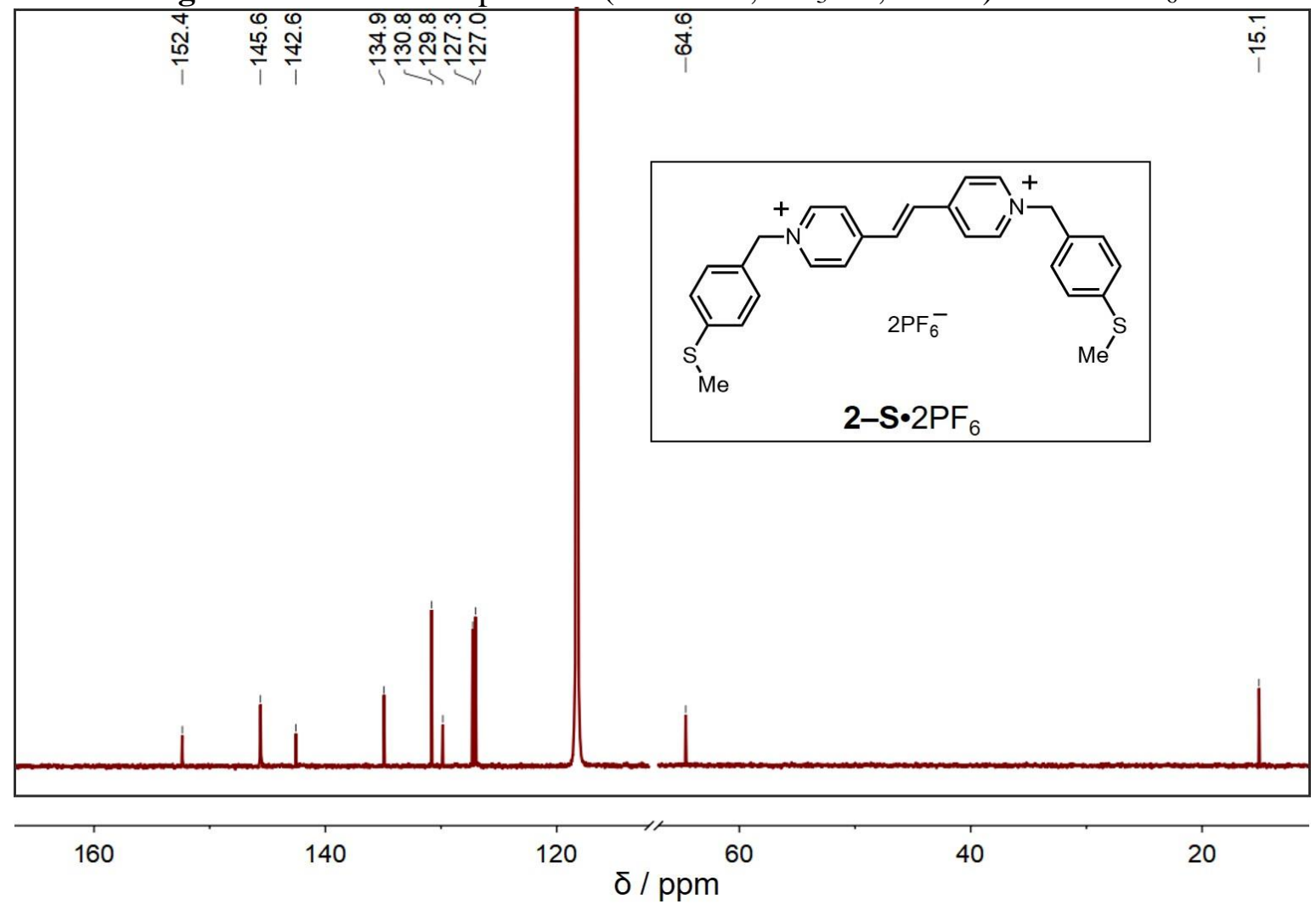

Figure S12. ${ }^{13} \mathrm{C}$ NMR spectrum $\left(125 \mathrm{MHz}, \mathrm{CD}_{3} \mathrm{CN}, 298 \mathrm{~K}\right)$ of $\mathbf{2}-\mathbf{S} \cdot 2 \mathrm{PF}_{6}$ 


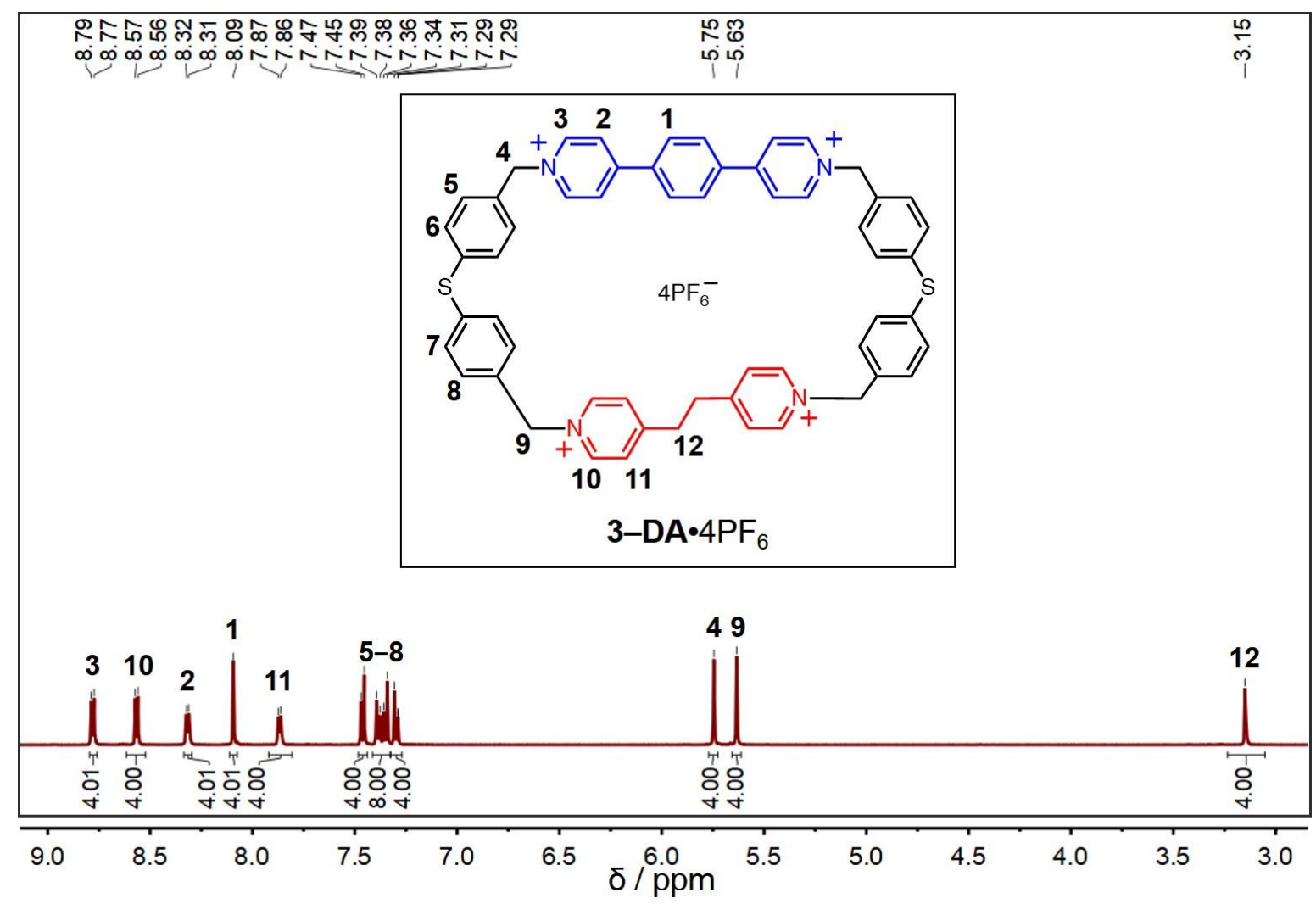

Figure S13. ${ }^{1} \mathrm{H}$ NMR spectrum $\left(500 \mathrm{MHz}, \mathrm{CD}_{3} \mathrm{CN}, 298 \mathrm{~K}\right)$ of 3-DA•4PF 6

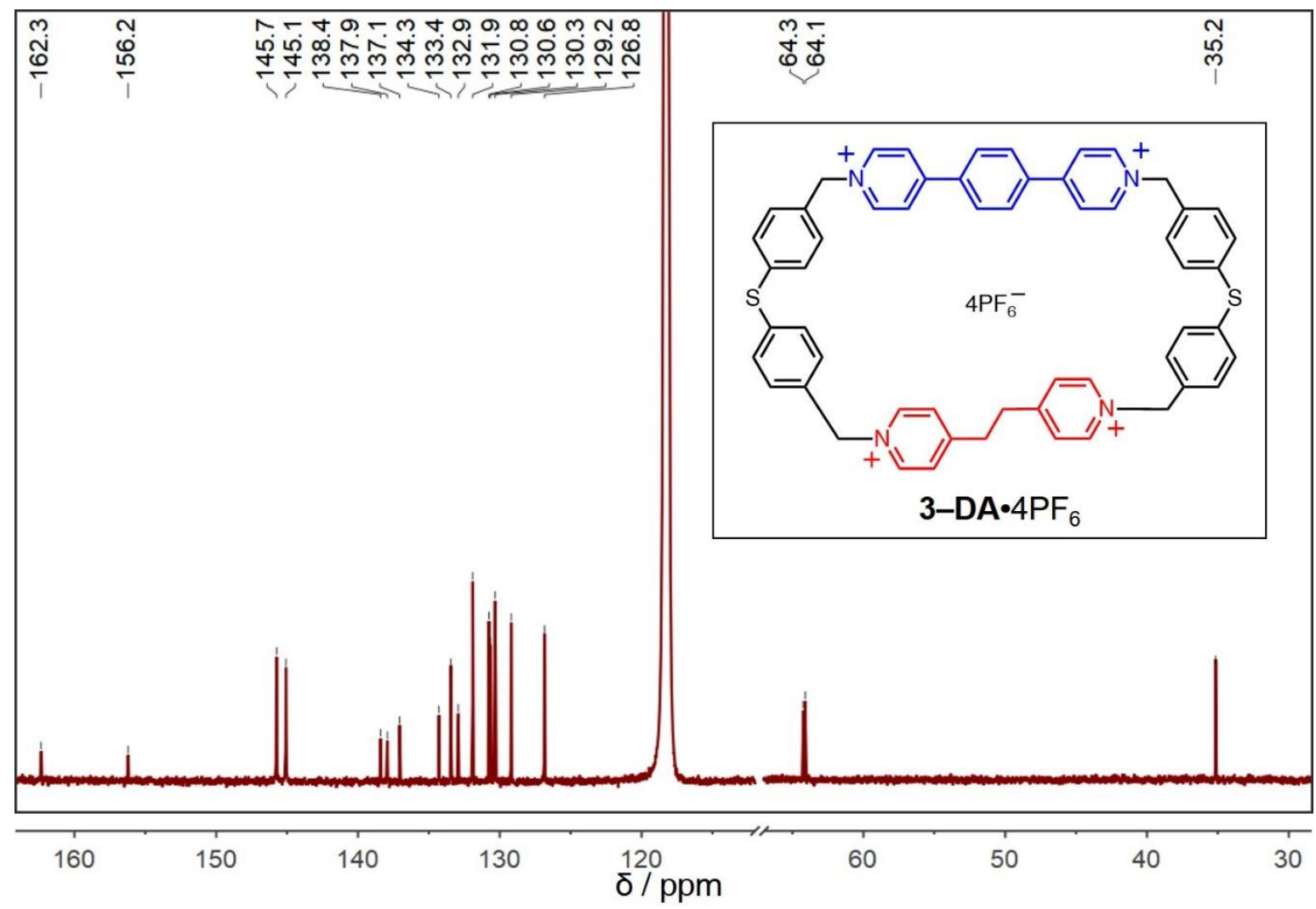

Figure S14. ${ }^{13} \mathrm{C}$ NMR spectrum $\left(125 \mathrm{MHz}, \mathrm{CD}_{3} \mathrm{CN}, 298 \mathrm{~K}\right)$ of 3-DA•4PF 6 


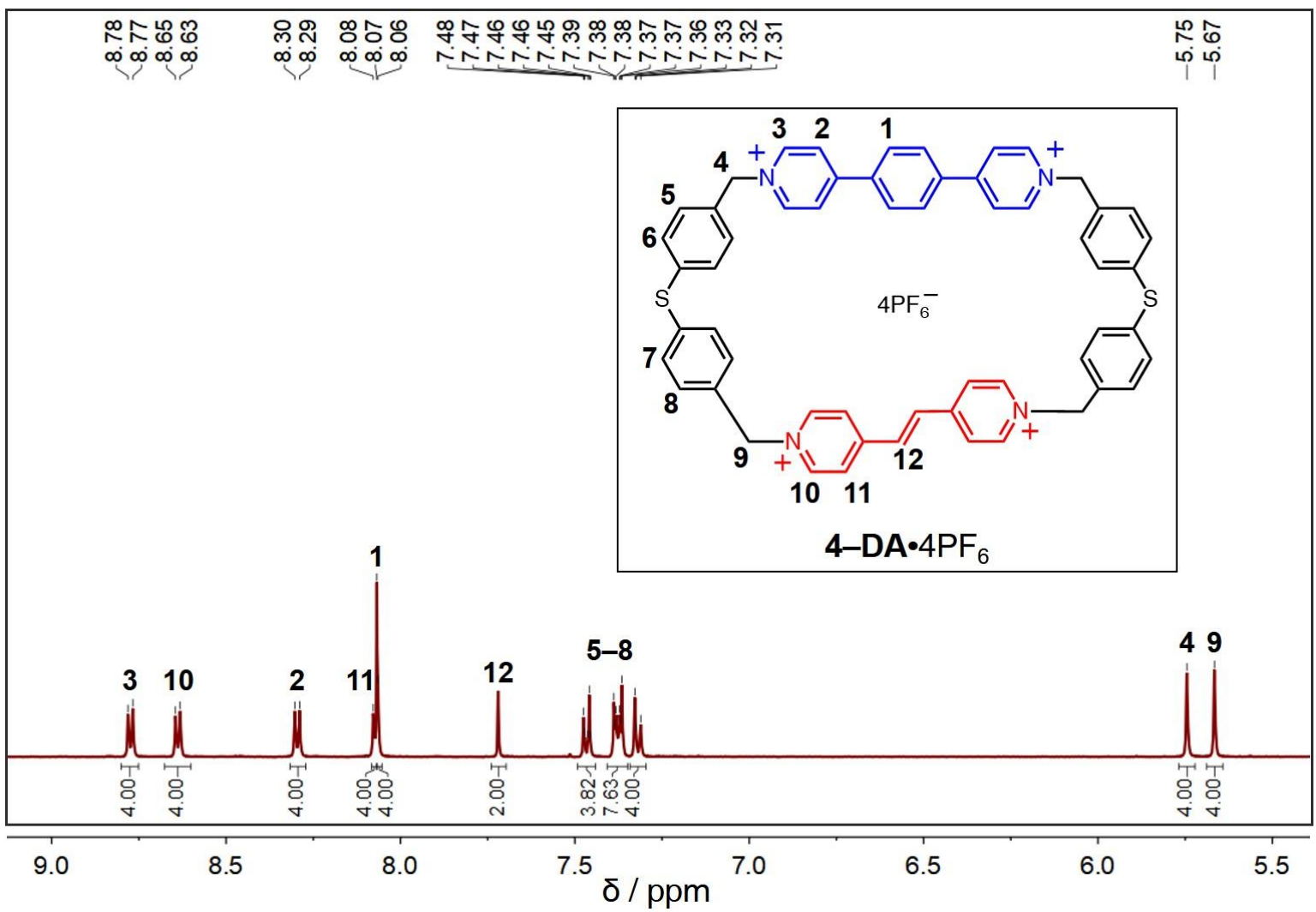

Figure S15. ${ }^{1} \mathrm{H}$ NMR spectrum $\left(500 \mathrm{MHz}, \mathrm{CD}_{3} \mathrm{CN}, 298 \mathrm{~K}\right)$ of 4-DA•4PF 6

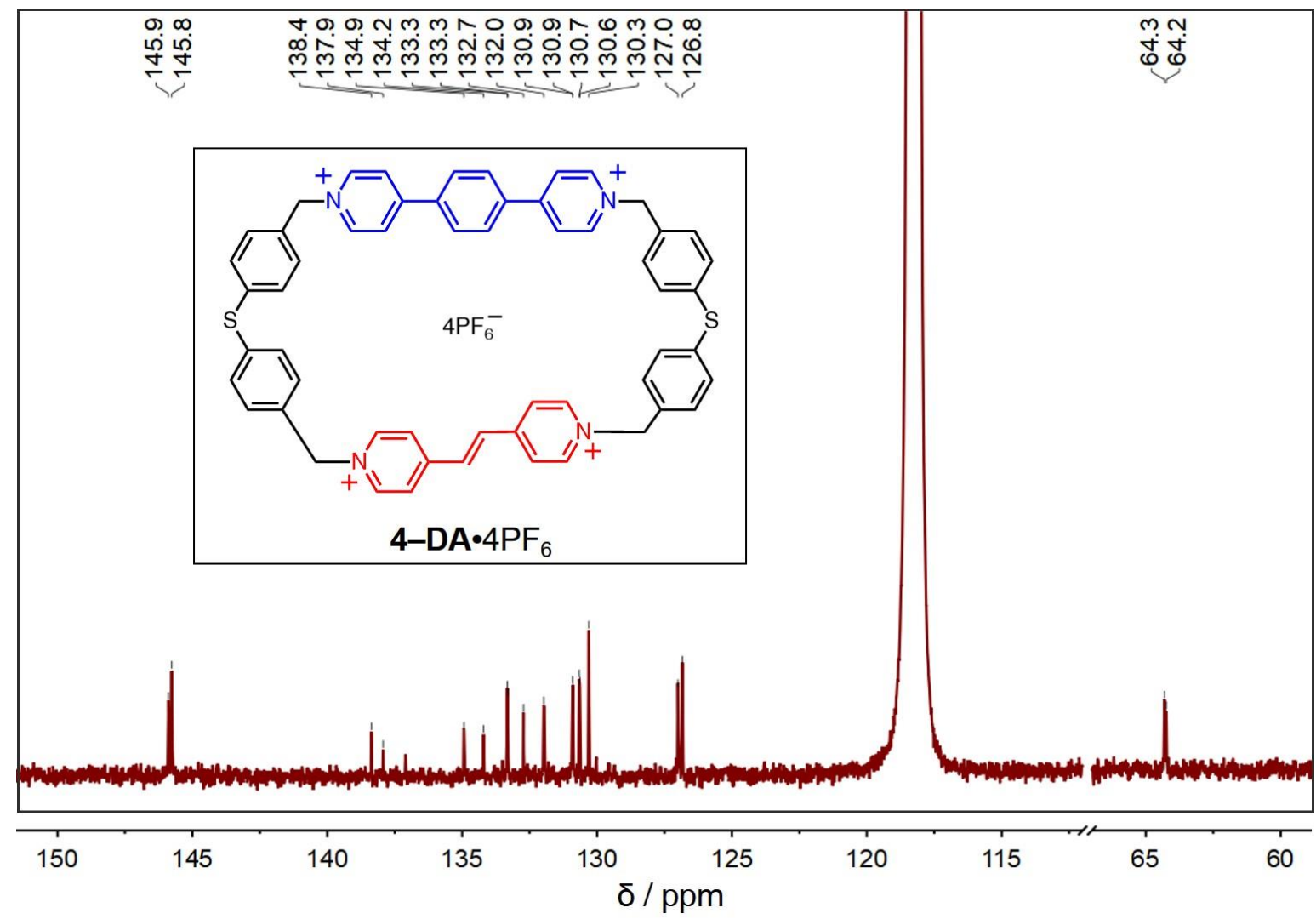

Figure S16. ${ }^{13} \mathrm{C}$ NMR spectrum $\left(125 \mathrm{MHz}, \mathrm{CD}_{3} \mathrm{CN}, 298 \mathrm{~K}\right)$ of $\mathbf{4}-\mathbf{D A} \cdot 4 \mathrm{PF}_{6}$ 


\section{Section D. Crystallographic Characterizations}

All crystallographic data are available free of charge from the Cambridge Crystallographic Data Centre (CCDC) via www.ccdc.cam.ac.uk/data_request/cif.

\section{(1) $1-S \cdot 2 P F_{6}$}

(a) Method. Compounds (1.5 mg) were dissolved in $\mathrm{MeCN}(1.0 \mathrm{~mL})$ and the mixture was passed through a $0.45-\mu \mathrm{m}$ filter into a tube. The tube was placed in a $20-\mathrm{mL}$ vial containing $\mathrm{Et}_{2} \mathrm{O}(\sim 3 \mathrm{~mL})$ and the vial was capped. Slow vapor diffusion of $\mathrm{Et}_{2} \mathrm{O}$ into the $\mathrm{MeCN}$ solution over the course of 4 days yielded single crystals of $\mathbf{1}-\mathbf{S} \cdot 2 \mathbf{P F}_{6}$. A suitable crystal was selected and the crystal was mounted on a MITIGEN holder with Paratone oil on a XtaLAB Synergy, Single source at home/near, HyPix diffractometer. The crystal was kept at 199.95(11) K during data collection. Using Olex $2^{2}$, the structure was solved with the ShelXT ${ }^{3}$ structure solution program using Intrinsic Phasing and refined with the $\mathrm{XL}^{4}$ refinement package using Least Squares minimisation. The solidstate (super)structure of $\mathbf{1}-\mathbf{S} \cdot 2 \mathrm{PF}_{6}$ is shown in Figure $\mathbf{2 a}$ and Figure S17.

(b) Crystal Parameters. $\mathrm{C}_{28} \mathrm{H}_{30} \mathrm{~N}_{2} \mathrm{~S}_{2}\left(\mathrm{PF}_{6}\right)_{2} . M_{\mathrm{r}}=748.60$. Crystal size $\left(0.194 \times 0.137 \times 0.026 \mathrm{~mm}^{3}\right)$. Triclinic, space group $P \overline{1}$ (no. 2), $a=6.03560(10), b=7089590(10), c=17.4772(2) \AA, \alpha=$ 89.5890(10), $\beta=82.5350(10), \gamma=73.3110(10)^{\circ}, V=790.658(19) \AA^{3}, Z=1, T=199.95(11) \mathrm{K}$, $\mu(\mathrm{CuK} \alpha)=3.359 \mathrm{~mm}^{-1}$, Dcalc $=1.572 \mathrm{~g} / \mathrm{mm}^{3}, 23998$ reflections measured $(10.214 \leq 2 \Theta \leq 158.534)$, 3258 unique $\left(R_{\text {int }}=0.0293, R_{\text {sigma }}=0.0162\right)$ which were used in all calculations. The final $R_{1}$ was $0.0979(I>2 \sigma(I))$ and $w R_{2}$ was 0.2452 (all data). CCDC Number: 2035268.

(c) Refinement Details. Distance restraints were imposed on the disordered $\mathrm{PF}_{6}{ }^{-}$anions and carbon-

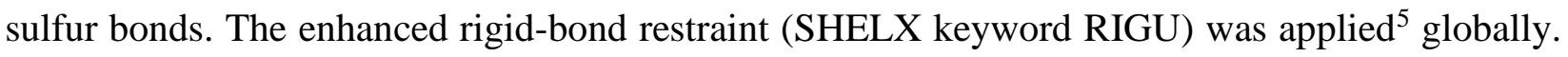
The disordered methyl carbon and sulfur atoms were restrained that its $U_{\mathrm{ij}}$ components approximate to isotropic. 


\section{(2) $2-S \cdot 2 P F_{6}$}

(a) Method. Compounds (1.0 mg) were dissolved in $\mathrm{MeCN}(1.0 \mathrm{~mL})$ and the mixture was passed through a $0.45-\mu \mathrm{m}$ filter into a tube. The tube was placed in a $20-\mathrm{mL}$ vial containing $\mathrm{Et}_{2} \mathrm{O}(\sim 3 \mathrm{~mL})$ and the vial was capped. Slow vapor diffusion of $\mathrm{Et}_{2} \mathrm{O}$ into the $\mathrm{MeCN}$ solution over the course of 3 days yielded single crystals of $\mathbf{2}-\mathbf{S} \cdot 2 \mathbf{P F}_{6}$. A suitable crystal was selected and the crystal was mounted on a MITIGEN holder with Paratone oil on a XtaLAB Synergy, R, DW system, HyPix diffractometer. The crystal was kept at $102(2) \mathrm{K}$ during data collection. Using Olex $2^{2}$, the structure was solved with the ShelXT ${ }^{3}$ structure solution program using Intrinsic Phasing and refined with the $\mathrm{XL}^{4}$ refinement package using Least Squares minimisation. The solid-state (super)structure of $\mathbf{1}-\mathbf{S} \cdot 2 \mathrm{PF}_{6}$ is shown in Figure $2 \mathbf{d}$ and Figure $\mathbf{S 2 0}$.

(b) Crystal Parameters. $\mathrm{C}_{28} \mathrm{H}_{28} \mathrm{~N}_{2} \mathrm{~S}_{2}\left(\mathrm{PF}_{6}\right)_{2} . M_{\mathrm{r}}=746.58$. Crystal size $\left(0.23 \times 0.19 \times 0.045 \mathrm{~mm}^{3}\right)$. Monoclinic, space group C2/c (no. 15), $a=16.97605(19) \AA, b=14.89031(17) \AA, c=12.79338(14)$ $\AA, \beta=106.6000(12)^{\circ}, V=3099.11(6) \AA^{3}, Z=4, T=102(2) \mathrm{K}, \mu(\mathrm{CuK} \alpha)=3.428 \mathrm{~mm}^{-1}$, Dcalc $=$ $1.600 \mathrm{~g} / \mathrm{mm}^{3}, 23905$ reflections measured $(8.05 \leq 2 \Theta \leq 156.986), 3199$ unique $\left(R_{\text {int }}=0.0279, R_{\text {sigma }}\right.$ $=0.0149)$ which were used in all calculations. The final $R_{1}$ was $0.0346(I>2 \sigma(I))$ and $w R_{2}$ was 0.0870 (all data). CCDC Number: 2035269.

(c) Refinement Details. Restraints on similar amplitudes separated by less than $1.7 \AA$ were imposed on the disordered fluorine atoms.

\section{(3) $3-D S \bullet 4 P F_{6}$}

(a) Method. Compounds (1.5 mg) were dissolved in $\mathrm{MeCN}(1.0 \mathrm{~mL})$ and the mixture was passed through a $0.45-\mu \mathrm{m}$ filter into a vial. The vial was placed in a $20-\mathrm{mL}$ vial containing $\mathrm{Et}_{2} \mathrm{O}(\sim 3 \mathrm{~mL})$ and the vial was capped. Slow vapor diffusion of $\mathrm{Et}_{2} \mathrm{O}$ into the $\mathrm{MeCN}$ solution over the course of 4 days yielded single crystals of $\mathbf{3}-\mathbf{D S} \bullet 4 \mathrm{PF}_{6}$. A suitable crystal was selected and the crystal was 
mounted on a MITIGEN holder in Paratone on a 'Bruker APEX-II CCD' diffractometer. The crystal was kept at $250.0 \mathrm{~K}$ during data collection. Using Olex2 ${ }^{2}$, the structure was solved with the $\mathrm{XT}^{4}$ structure solution program using Intrinsic Phasing and refined with the ShelXL ${ }^{3}$ refinement package using Least Squares minimisation. The solid-state (super)structure of $\mathbf{3}-\mathbf{D S} \cdot 2 \mathrm{PF}_{6}$ is shown in Figure 2B and Figure S18.

(b) Crystal Parameters. $\left[\mathrm{C}_{54} \mathrm{H}_{48} \mathrm{~N}_{4} \mathrm{~S}_{2}\left(\mathrm{PF}_{6}\right)_{4}\right]\left(\mathrm{CH}_{3} \mathrm{CN}\right)_{2} . M_{\mathrm{r}}=1455.05$. Crystal size $(0.242 \times 0.11 \times$ $0.02 \mathrm{~mm}^{3}$ ). Triclinic, space group $P \overline{1}, a=8.1564(15) \AA$, $b=10.9416(19) \AA, c=18.318(3) \AA, \alpha=$ 89.289(8), $\beta=80.851(8), \gamma=86.349(8)^{\circ}, V=1610.7(5) \AA^{3}, Z=1, T=250.0 \mathrm{~K}, \mu(\mathrm{CuK} \alpha)=2.702$ $\mathrm{mm}^{-1}$, Dcalc $=1.500 \mathrm{~g} / \mathrm{mm}^{3}, 18188$ reflections measured $(4.886 \leq 2 \Theta \leq 130.94), 5492$ unique $\left(R_{\text {int }}\right.$ $\left.=0.0298, R_{\text {sigma }}=0.0280\right)$ which were used in all calculations. The final $R_{1}$ was $0.0474(I>2 \sigma(I))$ and $w R_{2}$ was 0.1425 (all data). CCDC Number: 1954284.

(c) Refinement Details. The enhanced rigid-bond restraint (SHELX keyword RIGU) was applied ${ }^{5}$ as well as restraints on similar amplitudes separated by less than $1.7 \AA$ on the disordered $\mathrm{PF}_{6}{ }^{-}$ anions and acetonitrile solvent.

\section{(4) $3-D A \bullet 4 P F_{6}$}

(a) Method. Compounds (1.5 mg) were dissolved in $\mathrm{MeCN}(1.0 \mathrm{~mL})$ and the mixture was passed through a $0.45-\mu \mathrm{m}$ filter into a vial. The vial was placed in a $20-\mathrm{mL}$ vial containing $\mathrm{Et}_{2} \mathrm{O}(\sim 3 \mathrm{~mL})$ and the vial was capped. Slow vapor diffusion of $\mathrm{Et}_{2} \mathrm{O}$ into the $\mathrm{MeCN}$ solution over the course of 4 days yielded single crystals of $\mathbf{3}-\mathbf{D A} \cdot 4 \mathrm{PF}_{6}$. A suitable crystal was selected and the crystal was mounted on a MITIGEN holder with Paratone oil on a XtaLAB Synergy, Single source at offset/far, HyPix diffractometer. The crystal was kept at 99.99(11) K during data collection. Using Olex $2^{2}$, the structure was solved with the ShelXT ${ }^{3}$ structure solution program using Intrinsic Phasing and refined with the $\mathrm{XL}^{4}$ refinement package using Least Squares minimisation. The solid-state 
(super)structure of $\mathbf{1}-\mathbf{S} \cdot 2 \mathrm{PF}_{6}$ is shown in Figure $\mathbf{2 c}$ and Figure S19.

(b) Crystal Parameters. $\left[\mathrm{C}_{56} \mathrm{H}_{48} \mathrm{~N}_{4} \mathrm{~S}_{2}\left(\mathrm{PF}_{6}\right)_{4}\right]\left(\mathrm{CH}_{3} \mathrm{CH}_{2} \mathrm{O}\right)_{2} . M_{\mathrm{r}}=1495.10$. Crystal size $(0.594 \times$ $\left.0.281 \times 0.019 \mathrm{~mm}^{3}\right)$. Triclinic, space group $P \overline{1}, a=13.1563(3), b=13.9690(3), c=17.8427(5) \AA$, $\alpha=84.706(2), \beta=89.476(2), \gamma=78.978(2)^{\circ}, V=3204.80(14) \AA^{3}, Z=2, T=99.99(11) \mathrm{K}, \mu(\mathrm{MoK} \alpha)$ $=0.298 \mathrm{~mm}^{-1}$, Dcalc $=1.549 \mathrm{~g} / \mathrm{mm}^{3}, 92478$ reflections measured $(3.906 \leq 2 \Theta \leq 62.154), 17356$ unique $\left(R_{\text {int }}=0.0863, R_{\text {sigma }}=0.0739\right)$ which were used in all calculations. The final $R_{1}$ was 0.0869 $(I>2 \sigma(I))$ and $w R_{2}$ was 0.2381 (all data). CCDC Number: 2035270.

(c) Refinement Details. Distant restraints were imposed on the disordered anions. The enhanced

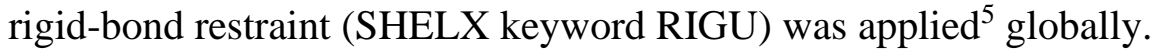

\section{(5) $4-D S \bullet 4 P F_{6}$}

(a) Method. Compounds (1.5 mg) were dissolved in $\mathrm{MeCN}(1.0 \mathrm{~mL})$ and the mixture was passed through a $0.45-\mu \mathrm{m}$ filter into a vial. The vial was placed in a $20-\mathrm{mL}$ vial containing $\mathrm{Et}_{2} \mathrm{O}(\sim 3 \mathrm{~mL})$ and the vial was capped. Slow vapor diffusion of $\mathrm{Et}_{2} \mathrm{O}$ into the $\mathrm{MeCN}$ solution over the course of 4 days yielded single crystals of $\mathbf{4}-\mathbf{D S} \bullet 4 \mathrm{PF}_{6}$. A suitable crystal was selected and the crystal was mounted on a MITIGEN holder with Paratone oil on a Bruker Kappa APEX CCD area detector diffractometer. The crystal was kept at $100.0 \mathrm{~K}$ during data collection. Using Olex $2^{2}$, the structure was solved with the ShelXT ${ }^{3}$ structure solution program using Intrinsic Phasing and refined with the $\mathrm{XL}^{4}$ refinement package using Least Squares minimisation. The solid-state (super)structure of 4-DS•4PF 6 is shown in Figure 2e and Figure S21.

(b) Crystal Parameters. $\left[\mathrm{C}_{54} \mathrm{H}_{44} \mathrm{~N}_{4} \mathrm{~S}_{2}\left(\mathrm{PF}_{6}\right)_{4}\right]\left(\mathrm{CH}_{3} \mathrm{CN}\right)_{2} . M_{\mathrm{r}}=1451.02$. Crystal size $(0.695 \times 0.405$ $\left.\times 0.02 \mathrm{~mm}^{3}\right)$. Triclinic, space group $P \overline{1}, a=6.2983(6), b=14.3663(15), c=17.6991(18) \AA, \alpha=$ 81.621(5), $\beta=87.434(5), \gamma=81.763(5)^{\circ}, V=1567.6(3) \AA^{3}, Z=1, T=100.0 \mathrm{~K}, \mu(\mathrm{CuK} \alpha)=2.776$ $\mathrm{mm}^{-1}$, Dcalc $=1.537 \mathrm{~g} / \mathrm{mm}^{3}, 14696$ reflections measured $(6.278 \leq 2 \Theta \leq 131.226), 5295$ unique 
$\left(R_{\text {int }}=0.0571, R_{\text {sigma }}=0.0685\right)$ which were used in all calculations. The final $R_{1}$ was $0.0595(I>$ $2 \sigma(I))$ and $w R_{2}$ was 0.1705 (all data). CCDC Number: 1954285.

(c) Refinement Details. no special refinement necessary.

\section{(6) $4-D A \bullet 4 P F_{6}$}

(a) Method. Compounds (1.5 mg) were dissolved in $\mathrm{MeCN}(1.0 \mathrm{~mL})$ and the mixture was passed through a $0.45-\mu \mathrm{m}$ filter into a vial. The vial was placed in a $20-\mathrm{mL}$ vial containing $\mathrm{Et}_{2} \mathrm{O}(\sim 3 \mathrm{~mL})$ and the vial was capped. Slow vapor diffusion of $\mathrm{Et}_{2} \mathrm{O}$ into the $\mathrm{MeCN}$ solution over the course of 4 days yielded single crystals of $\mathbf{4}-\mathbf{D A} \bullet 4 \mathrm{PF}_{6}$. A suitable crystal was selected and the crystal was mounted on a MITIGEN holder with Paratone oil on a XtaLAB Synergy R, DW system, HyPix diffractometer. The crystal was kept at $99.98(12) \mathrm{K}$ during data collection. Using Olex $2^{2}$, the structure was solved with the ShelXT ${ }^{3}$ structure solution program using Intrinsic Phasing and refined with the $\mathrm{XL}^{4}$ refinement package using Least Squares minimisation. The solid-state (super)structure of 4-DA $4 \mathrm{PF}_{6}$ is shown in Figure $2 \mathbf{f}$ and Figure S22.

(b) Crystal Parameters. $\mathrm{C}_{59.635} \mathrm{H}_{54.725} \mathrm{~F}_{24} \mathrm{~N}_{4.18} \mathrm{O}_{0.82} \mathrm{P}_{4} \mathrm{~S}_{2} . M_{\mathrm{r}}=1487.06$. Crystal size $(0.122 \times 0.098$ $\left.\times 0.049 \mathrm{~mm}^{3}\right)$. Triclinic, space group $P \overline{1}, a=12.5223(2) \AA, b=14.50871(17) \AA, c=18.0208(3)$ $\AA, \alpha=85.6689(11)^{\circ}, \beta=87.7291(13)^{\circ}, \gamma=79.3621(12)^{\circ}, V=3207.51(8) \AA^{3}, Z=2, T=99.98(12)$ $\mathrm{K}, \mu(\mathrm{CuK \alpha})=2.730 \mathrm{~mm}^{-1}$, Dcalc $=1.540 \mathrm{~g} / \mathrm{mm}^{3}, 103979$ reflections measured $(4.92 \leq 2 \Theta \leq$ $158.934), 13023$ unique $\left(R_{\text {int }}=0.0864, R_{\text {sigma }}=0.0383\right)$ which were used in all calculations. The final $R_{1}$ was $0.0781(I>2 \sigma(I))$ and $w R_{2}$ was 0.2203 (all data). CCDC Number: 2035271.

(c) Refinement Details. Distant restraints were imposed on the disordered $\mathrm{PF}_{6}^{-}$anions. The enhanced rigid-bond restraint (SHELX keyword RIGU) was applied ${ }^{5}$ on the disordered atoms as well as restraints on similar amplitudes separated by less than $1.7 \AA$. 
a

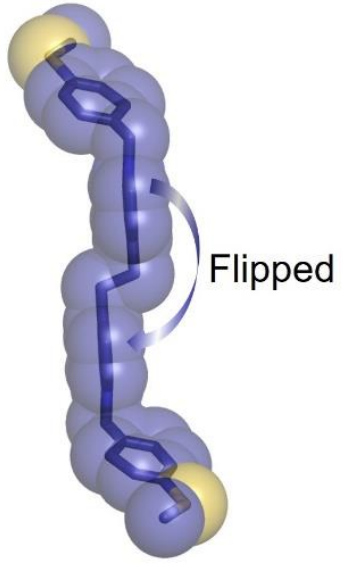

b

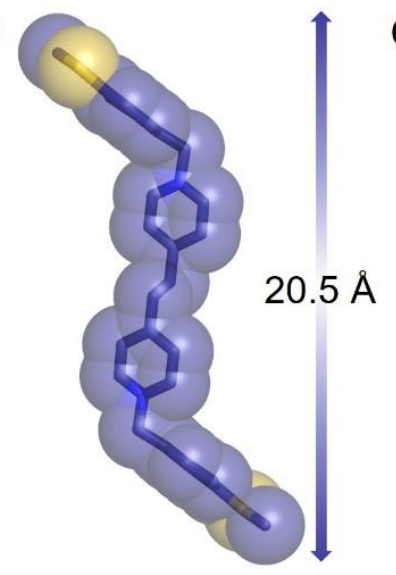

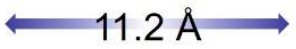

C

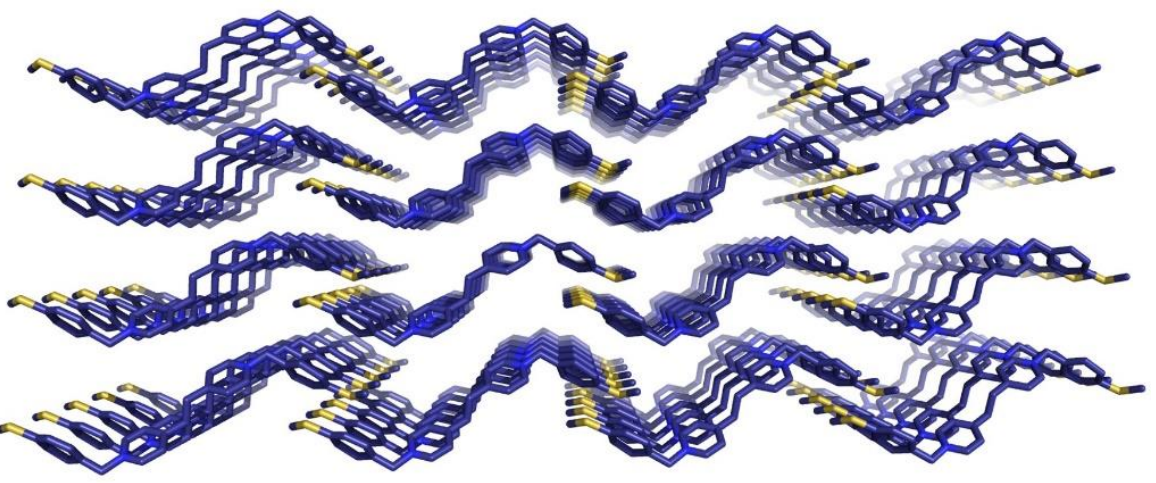

d

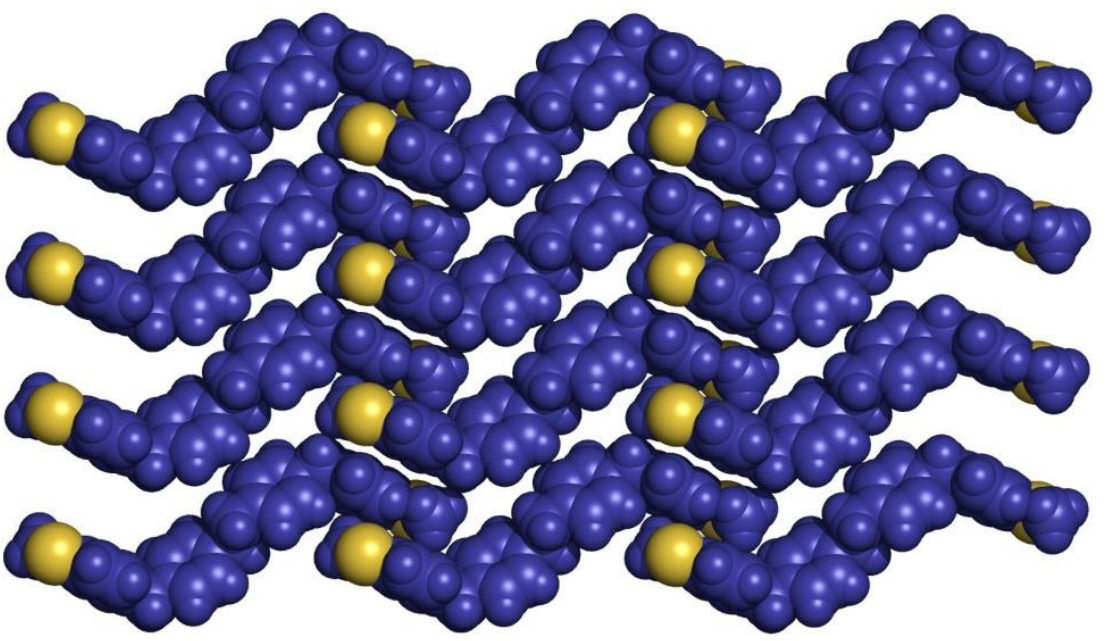

Figure S17. Solid-state (super)structures of single-channel $1-\mathrm{S}^{2+}$ incorporating a $\mathrm{DPA}^{2+}$

\section{backbone}

(a and b) Ball-and-stick representation, showing side-view (a) and front-view (b) of the singlechannel 1-S $\mathbf{S}^{2+}$, showing the S-S distance $(20.5 \AA)$ and the flipping of two pyridinium rings. The conjugation between these two pyridinium rings is broken because they do not locate on a common plane.

(c and d) Superstructures of $\mathbf{1}-\mathbf{S}^{\mathbf{2}+}$ showing a herringbone packing pattern. Hydrogen atoms in $\mathbf{a}-$ c and counterions in all Figures are omitted for the sake of clarity. 
a

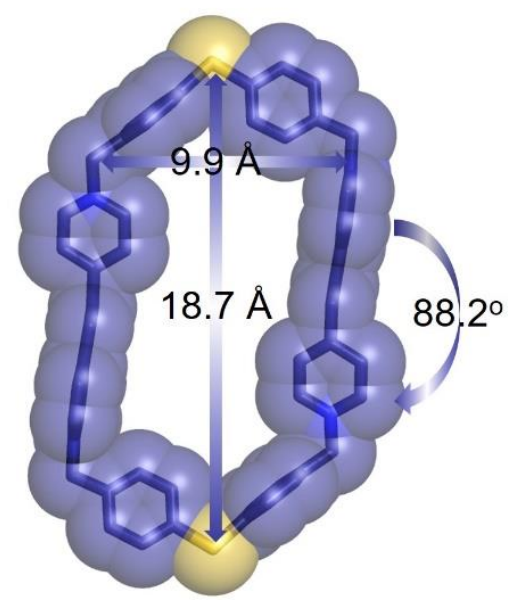

b

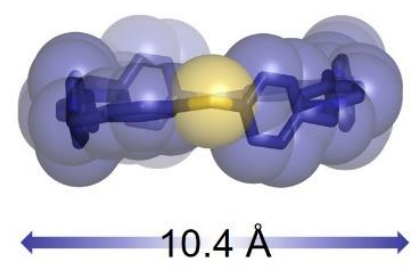

C

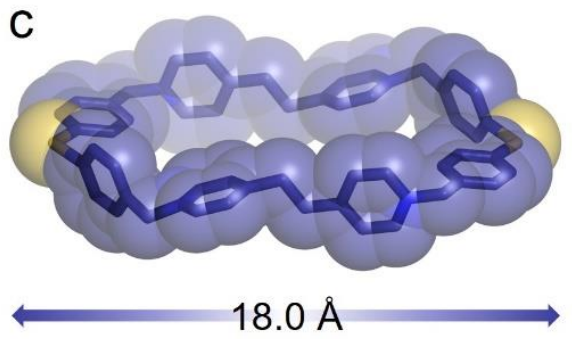

d
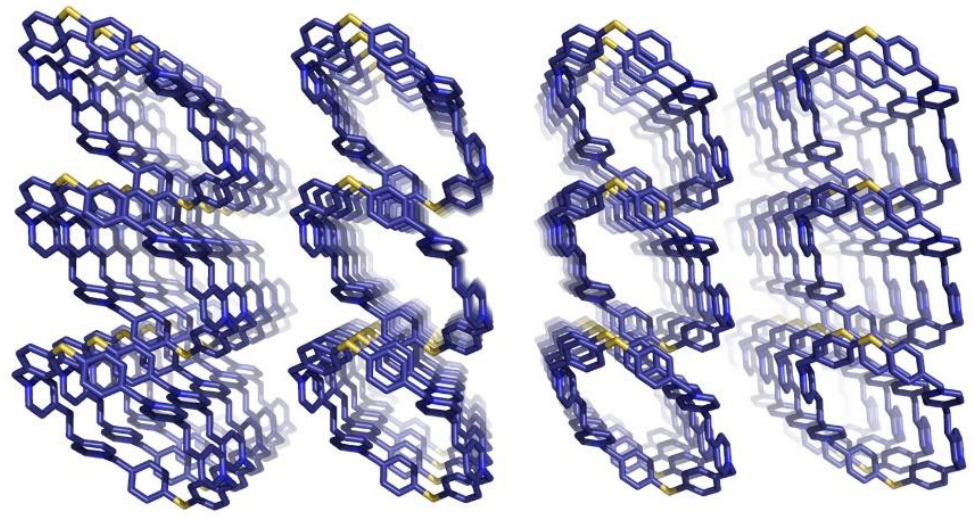

e

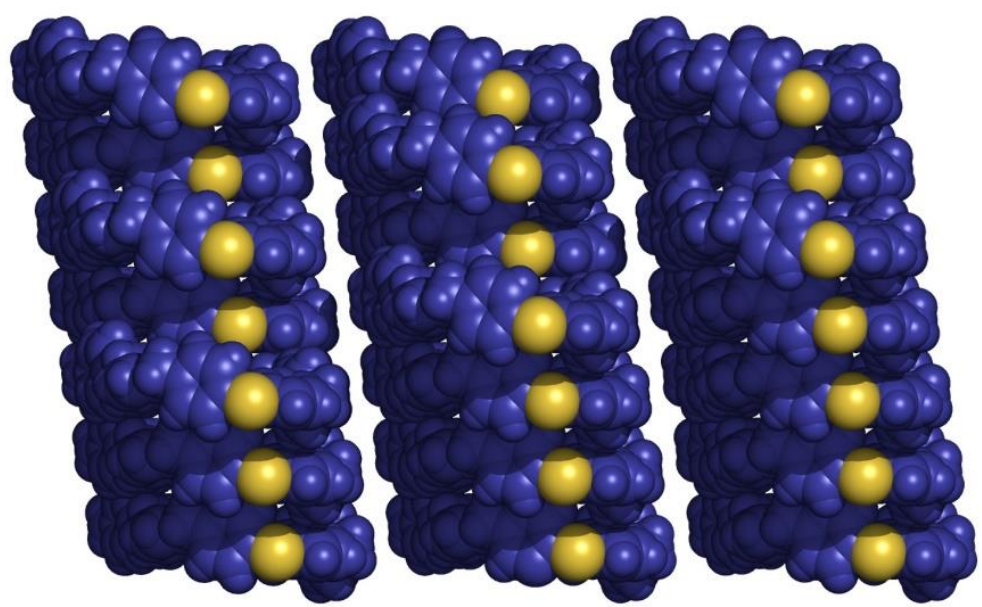

Figure S18. Solid-state (super)structures of double-channel symmetric cyclophane 3-DS ${ }^{4+}$ incorporating $\mathrm{DPA}^{2+}$ backbones

(a) Ball-and-stick representation, showing the S-S distance (18.7 $\AA), \mathrm{N}-\mathrm{N}$ distance $(9.9 \AA)$ and the torsional angle $\left(\sim 88.2^{\circ}\right)$ between two pyridinium rings.

(b and c) Ball-and-stick representations of different side-views of the cyclophane 3-DS ${ }^{4+}$.

(d and e) Superstructures of 3-DS $\mathbf{S}^{\mathbf{4}}$, showing that the cyclophanes are stacked layer-by-layer. Hydrogen atoms in $\mathbf{a}-\mathbf{d}$ and counterions in all Figures are omitted for the sake of clarity. 
a

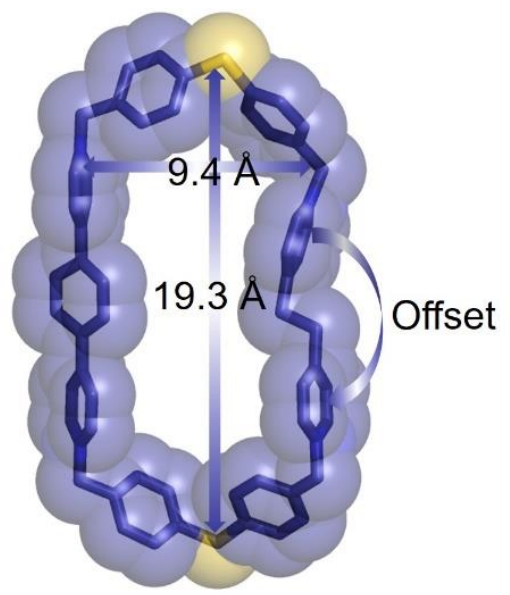

b

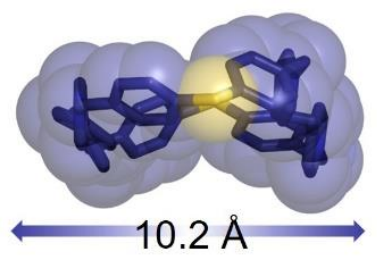

C

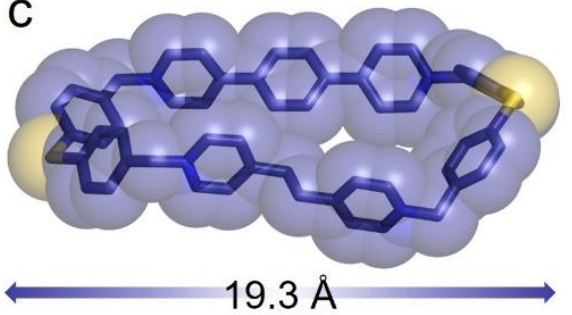

d

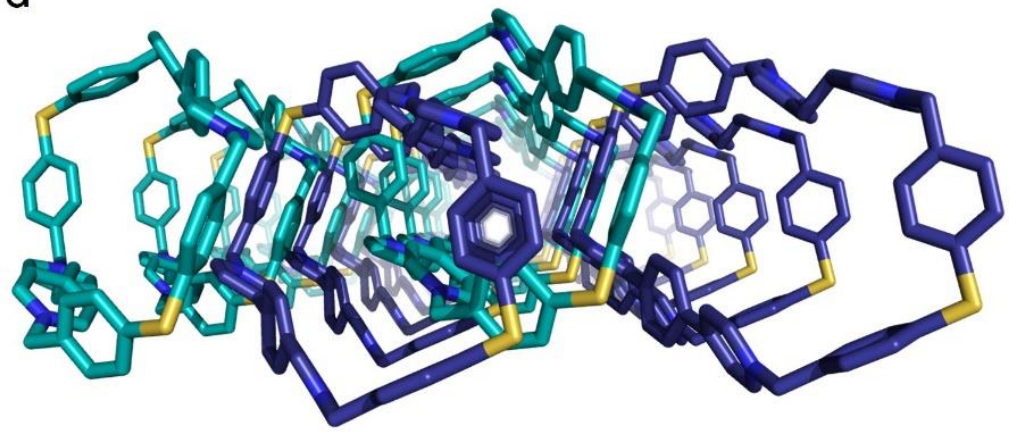

e

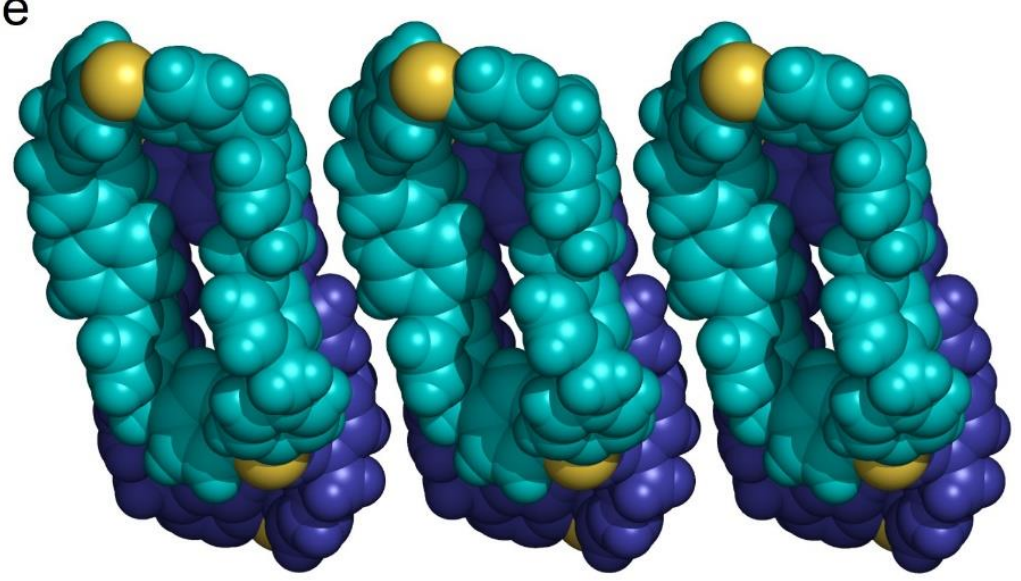

Figure S19. Solid-state (super)structures of double-channel asymmetric cyclophane 3-DA ${ }^{4+}$ incorporating a $\mathrm{DPA}^{2+}$ backbone

(a) Ball-and-stick representation, showing the S-S distance $(19.3 \AA), \mathrm{N}-\mathrm{N}$ distance $(9.4 \AA)$ and the flipping of two pyridinium rings. Though the torsional angle between two pyridinium rings is $\sim 18.4^{\circ}$, these two pyridinium rings are almost in two parallel planes with much less overlap in their $\pi$-orbitals.

(b and c) Ball-and-stick representations of different side-views of the cyclophane 3-DA $\mathbf{A}^{\mathbf{4 +}}$.

(d and e) Superstructures of 3-DA $\mathbf{A}^{4+}$, showing that the cyclophanes are stacked layer-by-layer. Hydrogen atoms in $\mathbf{a}-\mathbf{d}$ and counterions in all Figures are omitted for the sake of clarity. 


\section{a}

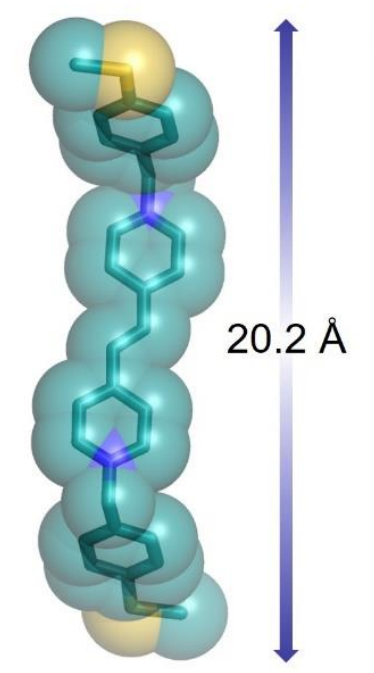

b

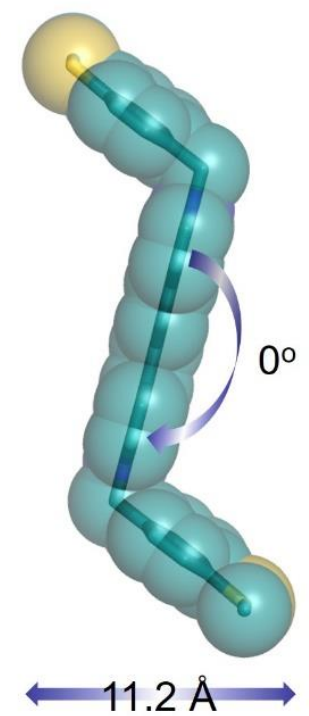

C

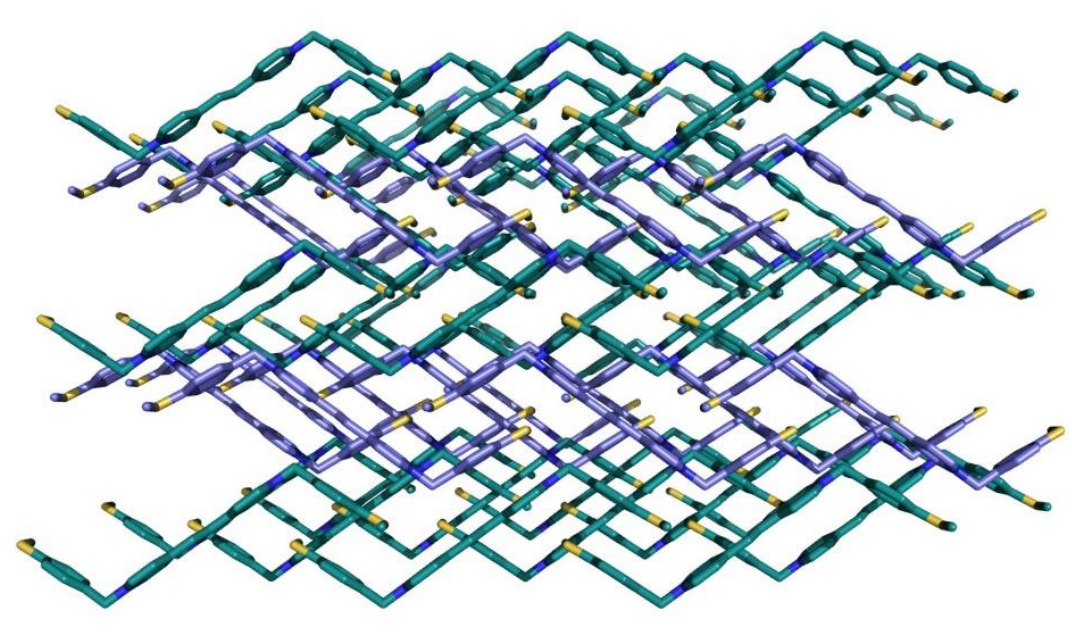

d

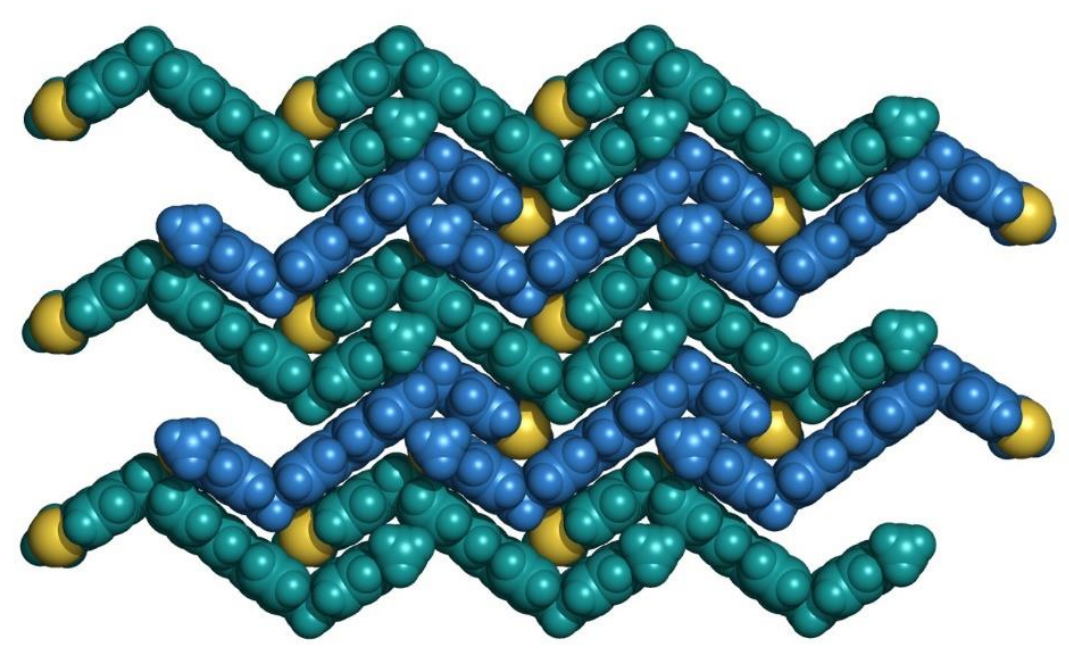

Figure S20. Solid-state (super)structures of single-channel $2-\mathrm{S}^{2+}$ incorporating a $\mathrm{DPE}^{2+}$ backbone

(a and b) Ball-and-stick representation, showing front-view (a) and side-view (b) of the singlechannel $2-\mathbf{S}^{2+}$ showing the S-S distance $(20.2 \AA)$ and the torsional angle $\left(\sim 0^{\circ}\right)$ between two pyridinium rings.

(c and d) Superstructures of $\mathbf{2}-\mathbf{S}^{2+}$, showing a herringbone packing pattern. Hydrogen atoms in $\mathbf{a}-$ c and counterions in all Figures are omitted for the sake of clarity. 
a

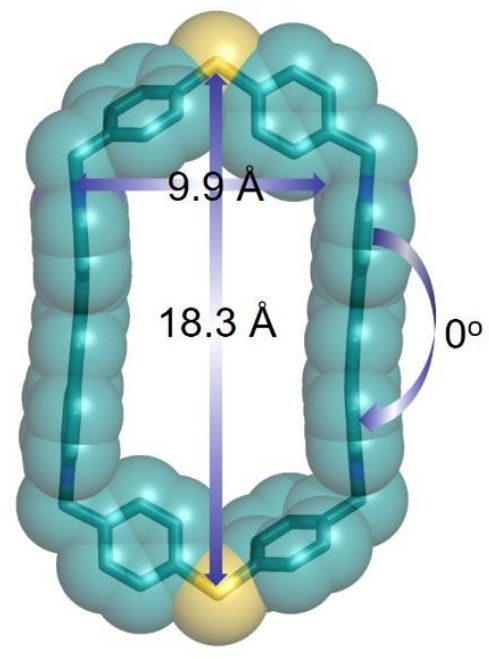

b
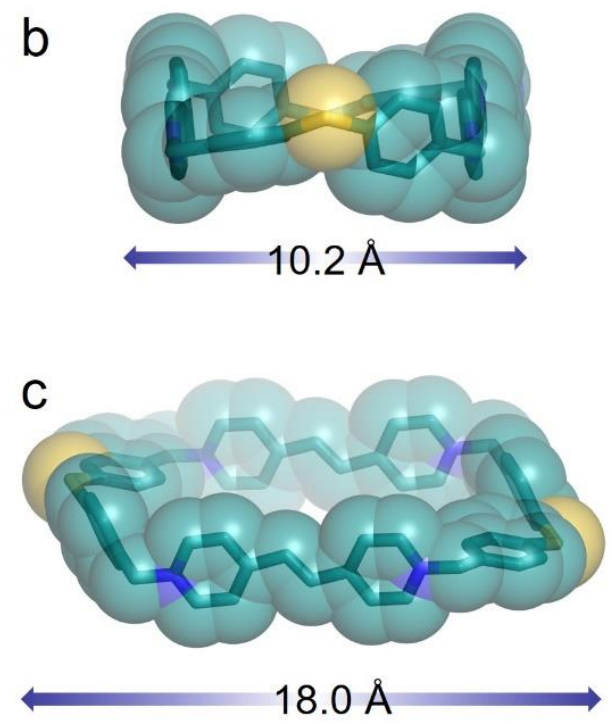

d
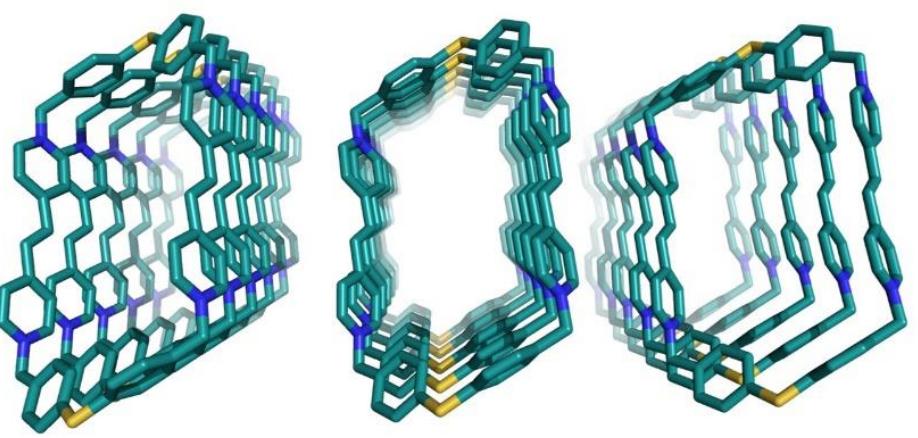

e

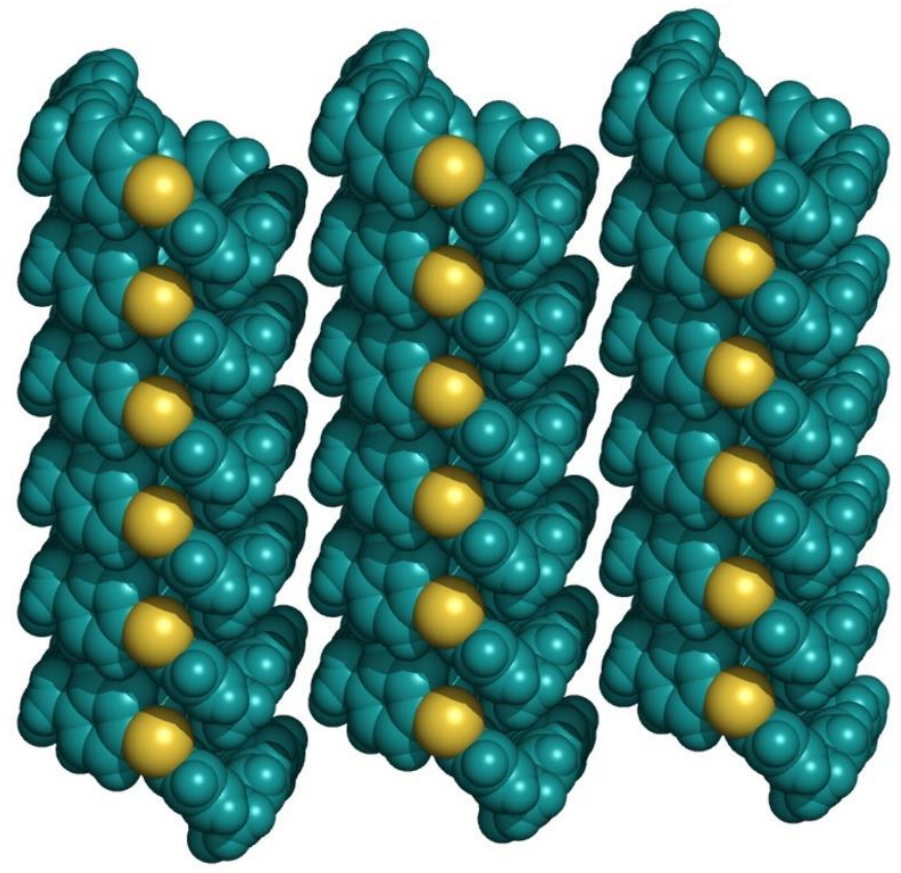

Figure S21. Solid-state (super)structures of double-channel symmetric cyclophane 4-DS ${ }^{4+}$ incorporating $\mathrm{DPE}^{2+}$ backbones

(a) Ball-and-stick representation, showing the S-S distance (18.3 $\AA$ ), N-N distance (9.9 $\AA$ ) and the torsional angle $\left(\sim 0^{\circ}\right)$ between two pyridinium rings.

(b and c) Ball-and-stick representation of different side-views of the cyclophane 4-DS ${ }^{4+}$.

(d and e) Superstructures of 4-DS ${ }^{4+}$ showing that the cyclophanes are stacked layer-by-layer. Hydrogen atoms in a-d and counterions in all Figures are omitted for the sake of clarity. 
a

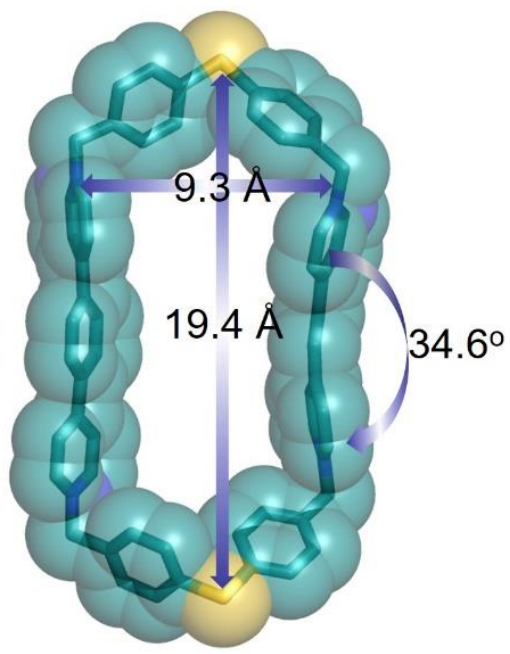

b

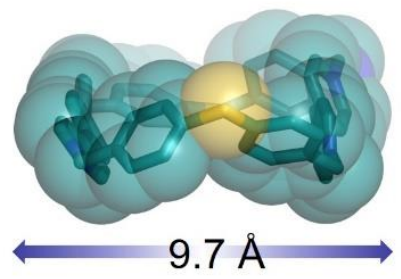

C

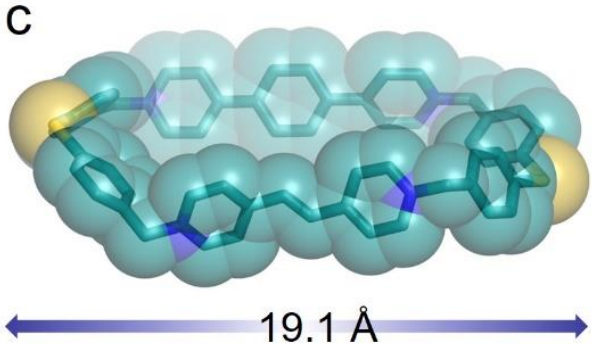

d

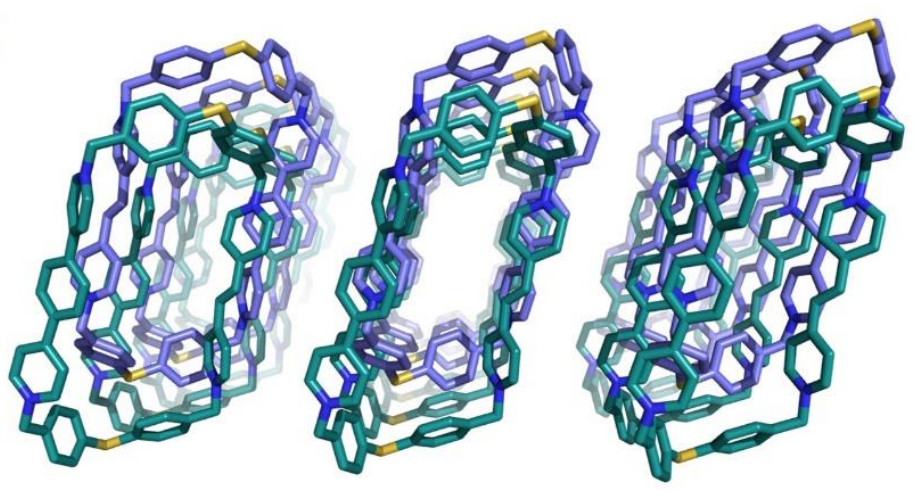

e

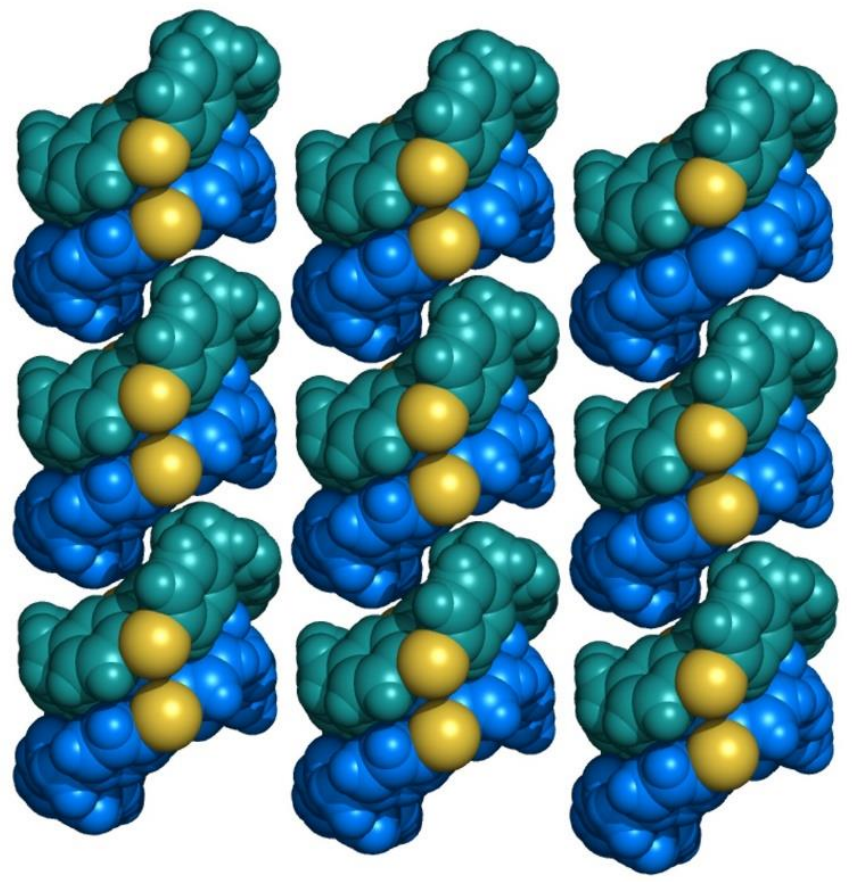

Figure S22. Solid-state (super)structures of double-channel asymmetric cyclophane 4-DA ${ }^{4+}$ incorporating a DPE ${ }^{2+}$ backbone

(a) Ball-and-stick representation, showing the S-S distance (19.4 $\AA$ ), N-N distance (9.3 $\AA$ ) and the torsional angle $\left(\sim 34.6^{\circ}\right)$ between two pyridinium rings. Two pyridinium rings are almost coplanar with much overlap in their $\pi$-orbitals.

(b and c) Ball-and-stick representations of different side-views of the cyclophane 4-DA ${ }^{4+}$.

(d and e) Superstructures of 4-DA ${ }^{4+}$, showing that the cyclophanes are stacked layer-by-layer. Hydrogen atoms in a-d and counterions in all Figures are omitted for the sake of clarity. 


\section{Section E. Supplemental Electrical Measurements}

STM-BJ Details. Scanning tunnelling microscope-based break junction (STM-BJ) measurements were performed using a custom-built STM that has been described ${ }^{6}$ previously. The hardware was controlled using custom software (written using LabView, National Instruments, USA) and experiments were conducted at room temperature under ambient conditions. STM Tips were prepared from electrochemically etched Au wire $(\varnothing=0.25 \mathrm{~mm}, 99.998 \%$, Alfa Aesar). The Au tip was then coated with an insulating layer to suppress background current in MeCN. The insulated tips were created by driving a mechanically cut Au tip through Apiezon wax. ${ }^{7}$ The Au substrates for solution measurements were prepared by evaporating $\sim 100 \mathrm{~nm} \mathrm{Au}(\geq 99.95 \%$, Alfa Aesar) at $\sim 1$ $\AA /$ s onto freshly cleaved mica or silicon substrates which were cleaned by Piranha solution before making measurements. The atomic contacts were freshly formed after breaking the connections between the $\mathrm{Au}$ tip and the substrate. Solutions $(10 \mu \mathrm{L})$ with target molecules $(0.1 \mathrm{mM})$ was dropped directly onto the Au substrate, which was used for further STM-BJ experiments.

In the case of STM-BJ measurements, the Au tip was controlled firstly by a stepper motor (Harmonic Drive, LA-30B-10-F) to obtain the approximate position to contact the substrate (less than $1 \mu \mathrm{m}$ ). Thereafter, the tip is controlled by a piezo stack (Thorlabs, PC4FL; max drive voltage, $150 \mathrm{~V}$; displacement, $4.6 \mu \mathrm{m} \pm 15 \%$ ) with the voltage applied from 0 to $10 \mathrm{~V}$, with the approach/retract at the speed of $10 \mathrm{~nm} / \mathrm{s}$. There is also a feedback system in the setup: when the voltage is changed in the piezo stack from 0 to $10 \mathrm{~V}$ one cannot contact $\mathrm{Au}$ tips and substrates or break the junction to the detecting limit of the amplifier (about $1 \mathrm{pA}$ ), otherwise the motor would take control of the movement of the tips to offset the distances between tips and substrates. During the repeating breaking and re-connecting operation, the bias was kept at $100 \mathrm{mV}$ and the real-time conductance was recorded using a home-built $I-V$ converter $^{8}$ with a sampling rate of $20 \mathrm{kHz}$. 
Data Analysis. Conductance was measured as a function of the tip-substrate displacement as the tip was pushed repeatedly into the substrate to reach a conductance of $>5 G_{0}$ (where $G_{0}=2 e^{2} / h, e$ is elementary charge, $h$ is Planck constant) and then retracted 5-10 nm (at $10 \mathrm{~nm} / \mathrm{s}$ ) to break the contact. In the measurement of single-molecule conductance, thousands of individual single traces are recorded in each experiment and a statistical approach without data selection is applied to determine the most probable conductance and stretching distance. All the conductance traces were used for analyses as reported in a previous paper. ${ }^{6}$ 1D-Conductance histograms were constructed by collecting all individual traces with a bin size of 1100 for $\log \left(G / G_{0}\right)$ from -10 to +1 , and 1000 for $\Delta z$ from -0.5 to $3 \mathrm{~nm}$. The conductance distribution was extracted by calculating the data density in each bin. The peak shift in a conductance histogram was determined by Gaussian fitting, which represents the most probable molecular conductance.

2D Conductance-displacement histograms were plotted by overlapping each individual trace with a bin size of 1100 for $\log \left(G / G_{0}\right)$ from -10 to +1 , and 1000 for $\Delta z$ from -0.5 to $3 \mathrm{~nm}$. All traces were aligned with a relative zero point $(\Delta z=0)$ at $G=0.5 G_{0}$. Then the $2 \mathrm{D}$ conductance distribution versus the relative distance was constructed by the data counts in each bin. In order to construct the displacement distribution histograms, firstly the relative stretching distance, $\Delta z$, was determined from the position where the conductance is $0.5 G_{0}$ (after the rupture of the gold-gold atomic break at $G_{0}$ ), to the molecular conductance region, just before the end of molecular plateau. The peak represents the most probable plateau length. In order to find the absolute displacement, $z^{*}$, which is related to the most probable length of molecular junction, the relative displacements were corrected by adding the snap-back distance, $\Delta z_{\text {corr }}$, to the relative displacement $\Delta z$, namely, $z^{*}=\Delta z$ $+\Delta z_{\text {corr. }}$ Referring to previous result, ${ }^{9} \Delta z_{\text {corr }}$ was determined experimentally to be $0.5 \pm 0.1 \mathrm{~nm}$. 

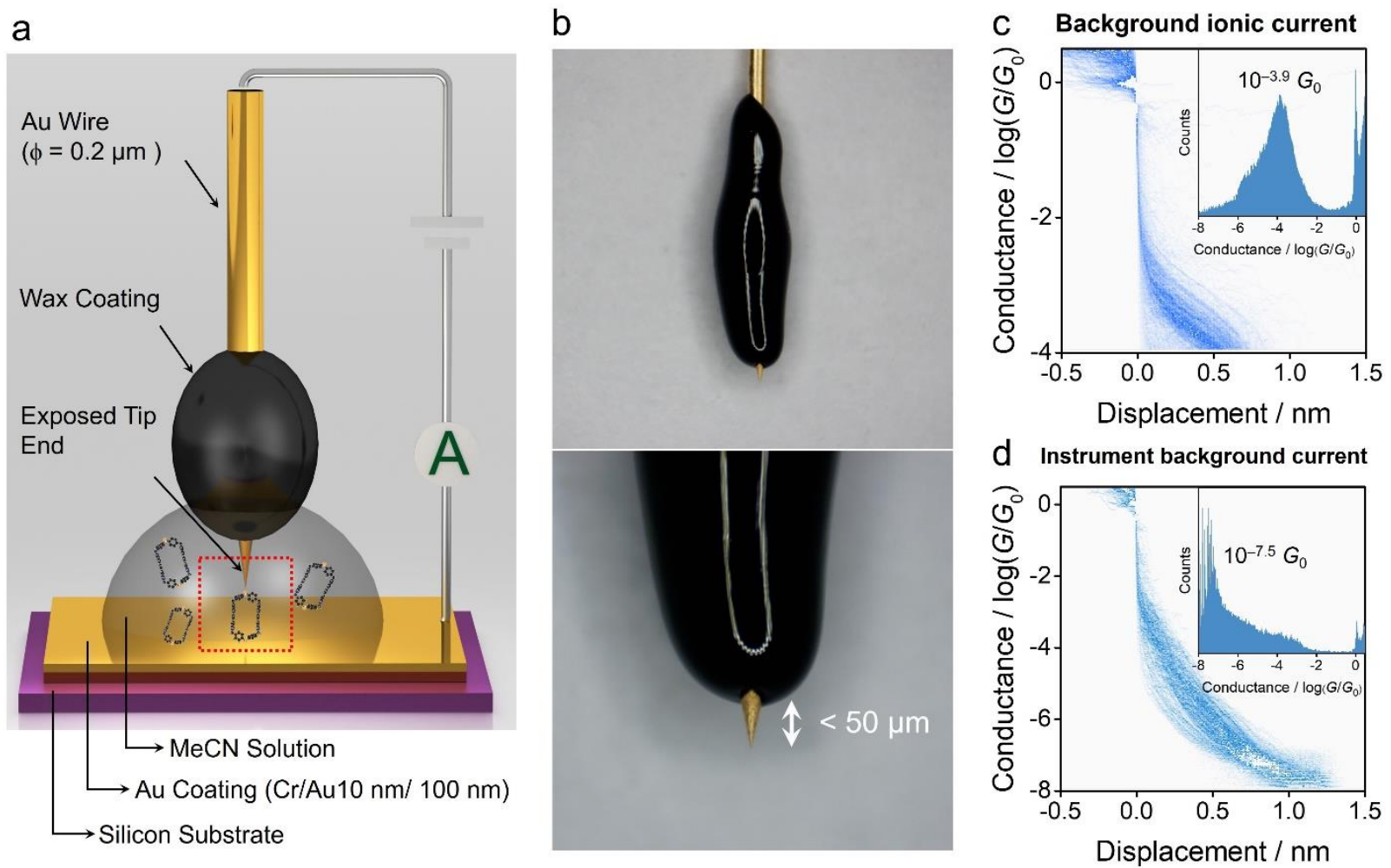

Figure S23. Experimental STM-BJ set-up and the evaluation of background current

(a) Schematic of the STM-BJ measurement in a solution environment.

(b) Optical microscopy showing the end of the wax coated STM tip. The tip we used was an electrochemically etched Au wire $(\Phi=0.25 \mathrm{~mm})$. After etching, the Au tip was coated with an insulating wax before measurements in a solution of the target clusters in MeCN. In order to suppress the ionic background current of $\mathrm{MeCN}$, the tip end exposed to environment should be shorter than $\sim 50 \mu \mathrm{m}$.

(c and d) control experiments in pure $\mathrm{MeCN}$ without targeting molecules before (C) and after (D) wax coating. The results showed that, without coating, the background ionic conductance is around $10^{-3.9} G_{0}$, which covers the signals of most molecules. After coating, however, the background conductance decreases to $\sim 10^{-7.5} G_{0}$, almost 2 to 3 orders of magnitude lower than the conductance level of molecules $\left(10^{-2.5}\right.$ to $\left.10^{-5.8} G_{0}\right)$. 
Table S1. Overview of primary structural and conductance results

\begin{tabular}{|c|c|c|c|c|c|c|c|}
\hline $\begin{array}{l}\text { Material } \\
\text { Index }\end{array}$ & Compound & Backbone & $\boldsymbol{\theta}^{a} / 0$ & $L^{b} / \AA$ & $z^{\star c} / \AA$ & $\begin{array}{c}\mathbf{H C}^{d} / \\
\log \left(G / G_{0}\right)\end{array}$ & $\begin{array}{c}\mathbf{L C} / \\
\log \left(G / G_{0}\right)\end{array}$ \\
\hline \multirow{2}{*}{1} & $3-S^{2+}$ & $\mathrm{DPA}^{2+}$ & 89.3 & 18.5 & $18.1 \pm 0.2$ & -4.01 & -5.46 \\
\hline & $4-S^{2+}$ & $\mathrm{DPE}^{2+}$ & 0 & 18.2 & $18.0 \pm 0.2$ & -4.02 & -5.55 \\
\hline \multirow{2}{*}{2} & $3-\mathrm{DS}^{4+}$ & $\mathrm{DPA}^{2+}$ & 88.2 & 18.7 & $17.3 \pm 0.2$ & NA & -4.11 \\
\hline & 4-DS ${ }^{4+}$ & $\mathrm{DPE}^{2+}$ & 0 & 18.3 & $17.2 \pm 0.1$ & NA & -3.82 \\
\hline \multirow{2}{*}{3} & $1-S^{2+}$ & $\mathrm{DPA}^{2+}$ & Offsetting & 20.5 & $18.1 \pm 0.2$ & -2.95 & -4.48 \\
\hline & $2-S^{2+}$ & $\mathrm{DPE}^{2+}$ & 0 & 20.2 & $18.3 \pm 0.2$ & -2.65 & -4.61 \\
\hline \multirow{2}{*}{4} & $3-\mathrm{DA}^{4+}$ & $\mathrm{DPA}^{2+}$ & Offsetting & 19.3 & $17.1 \pm 0.2$ & -3.85 & -5.65 \\
\hline & 4-DA ${ }^{4+}$ & $\mathrm{DPE}^{2+}$ & 34.6 & 19.4 & $17.8 \pm 0.3$ & -3.70 & -5.55 \\
\hline
\end{tabular}

a. $\theta$ is the torsional angle between two pyridinium rings.

b. $\quad L$ is the $\mathrm{S}-\mathrm{S}$ distance obtained from single-crystal structures or DFT optimized structures.

c. $z^{*}$ is the absolute displacement which is related to the most probable length of molecular junction. To find the $z^{*}$, the relative displacements were corrected by adding the snap-back distance

$$
z^{*}=\Delta z+\Delta z_{\text {corr }}
$$

where $\Delta z$ is the relative displacements obtained from the distributions of conductancesdisplacement traces; $\Delta z_{\text {corr }}$ is the snap-back distance. Referring to previous result, ${ }^{9} \Delta z_{\text {corr }}$ was determined experimentally to be $0.5 \pm 0.1 \mathrm{~nm}$.

d. $\log \left(G / G_{0}\right)$ where $G_{0}=2 e^{2} / h$ represents the quantum conductance

Their HC levels are slightly lower than the values (Table $\mathbf{S 1}$ ) for $\mathbf{1}-\mathbf{S} \cdot 2 \mathrm{PF}_{6}$ and $\mathbf{2}-\mathbf{S} \cdot 2 \mathrm{PF}_{6}$ because the thiophenyl anchors form weaker contacts to Au than do the thiomethyl anchors. Moreover, the portion $(24 \%)$ of the HC state is larger than that (19\%) in molecules with -SMe anchors. This difference is because some portions of the $\mathrm{HC}$ states belong to the short contact between diphenylthioether sulfur and pyridinium nitrogen atoms. 

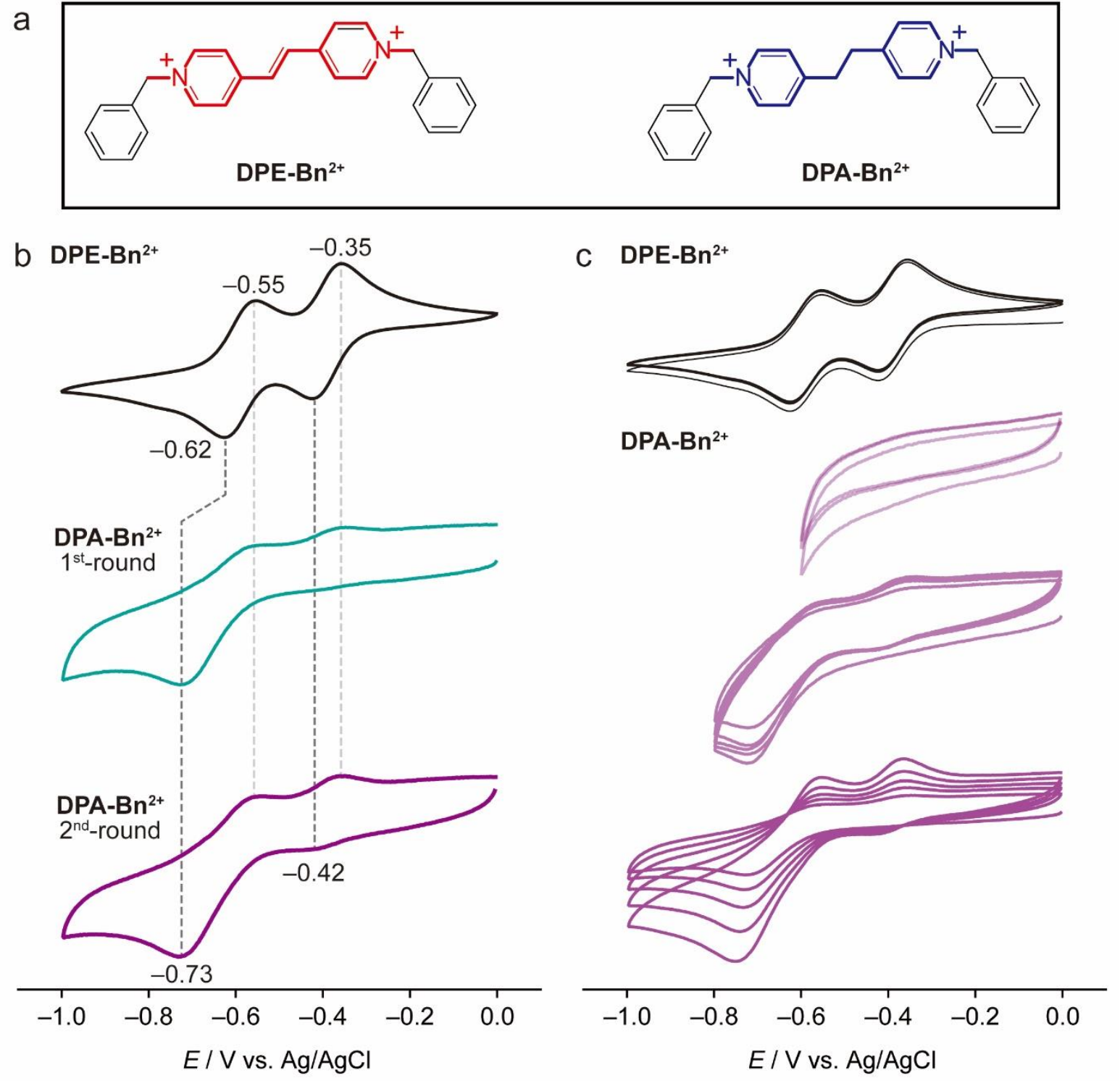

Figure S24. Cyclic voltammograms (CVs) analysis on control compounds

(a) Structural formulas for the control compounds DPE-Bn ${ }^{2+}$ (left) and DPA-Bn ${ }^{2+}$ (right).

(b and c) CV showing evidence for $\mathrm{DPA}^{2+}$-to-DPE ${ }^{2+}$ transformation in control compound DPA$\mathrm{Bn}^{2+}$.

(b, top) is a reductive $\mathrm{CV}\left(\mathrm{MeCN}, 0.1 \mathrm{M} \mathrm{TBAPF}_{6}, 100 \mathrm{mV} \mathrm{s}^{-1}\right)$ of DPE-Bn' ${ }^{2+}$, showing a reversible two-electron redox process.

(b, middle) illustrates a $1^{\text {st }}$-round CV scan of DPA-Bn ${ }^{2+}$ which is not reversible. The potential at $0.73 \mathrm{~V}$ corresponding to the reduction of isolated pyridinium rings. The potential is similar to that 
$(-0.73 \mathrm{~V})$ of $\mathbf{2}-\mathbf{S}^{\mathbf{2 +}}$ but much smaller than that $(-1.30 \mathrm{~V})$ of DPA-Me $\mathbf{2}^{\mathbf{2}}$, indicating that the benzyl substitution can stabilize the pyridinium radicals.

(b, bottom) shows the second round CV scan demonstrating a two-electron redox process which resembles a superposition of the two voltammograms recorded for $\mathbf{D P E}-\mathbf{B} \mathbf{n}^{2+}$ and first round of DPA-Bn ${ }^{2+}$, indicating that both of these two species are occurring in this mixture.

(c, top) CV scans of DPE-Bn ${ }^{2+}$ with 5 cycles showing the reversibility of the redox process.

(c, bottom) CV scans of DPA-Bn ${ }^{2+}$ with difference potential range showing the dependence of highest potential needed to trigger the dehydrogenation.

From top to bottom: $-0.6 \mathrm{~V}$ (no reaction), $-0.8 \mathrm{~V}$ (dehydrogenation), and $-1.0 \mathrm{~V}$ (dehydrogenation).
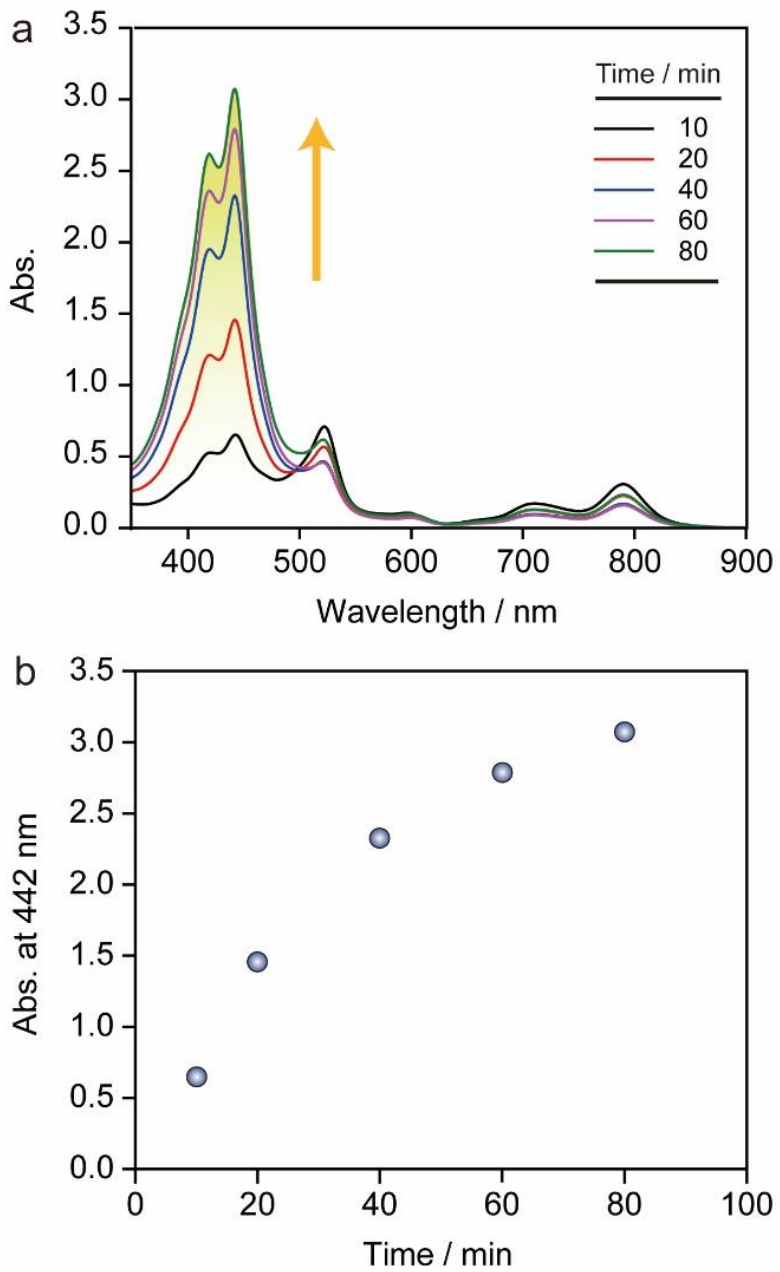

Figure S25. Monitoring of dehydrogenation performed in controlled potential electrolysis (CPE) apparatus 
(a) UV-Vis absorption spectra of $\mathbf{1}-\mathbf{S} \cdot 2 \mathrm{PF}_{6}$, which were obtained by increasing the electrolysis time. The CPE experiment was performed inside a plastic glovebox filled with $\mathrm{N}_{2}$ using a homebuilt electrolysis apparatus. The potential was set at $-1.0 \mathrm{~V}$ referenced to $\mathrm{Ag} / \mathrm{AgCl}$. All spectra were recorded in a sealed cuvette at $298 \mathrm{~K}$.

(b) Absorbance intensity changes at $442 \mathrm{~nm}$ of $\mathbf{1}-\mathbf{S} \cdot 2 \mathrm{PF}_{6}$ upon increasing the electrolysis time. The electrochemically dehydrogenation of $\mathbf{1}-\mathbf{S} \cdot 2 \mathrm{PF}_{6}$ in solution saturates after $\sim 2 \mathrm{~h}$ electrolysis in $\mathrm{N}_{2}$ glovebox.

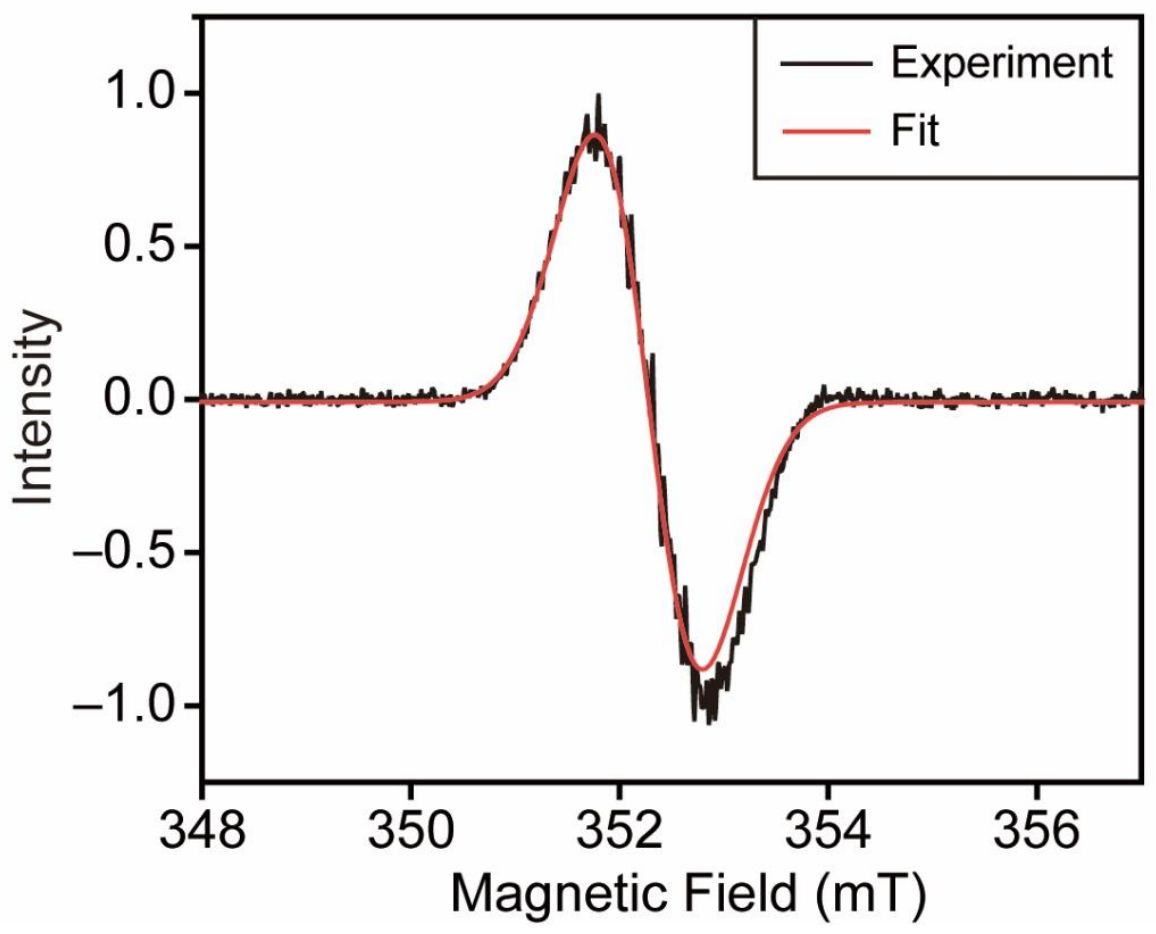

Figure S26. EPR spectra of radical cationic intermediate species DPE ${ }^{\cdot+}$

EPR Spectra were recorded using a Bruker Elexsys E580 X-band EPR spectrometer. EPR Samples were prepared by CPE experiments on $\mathbf{1}-\mathbf{S} \cdot 2 \mathrm{PF}_{6}$ at a reduction potential of $-1.0 \mathrm{~V}$ for $2 \mathrm{~h}$. The solution was transferred into $1.8 \mathrm{~mm}$ o.d. quartz tubes and sealed with a clear ridged UV doming epoxy in an Ar glovebox. 

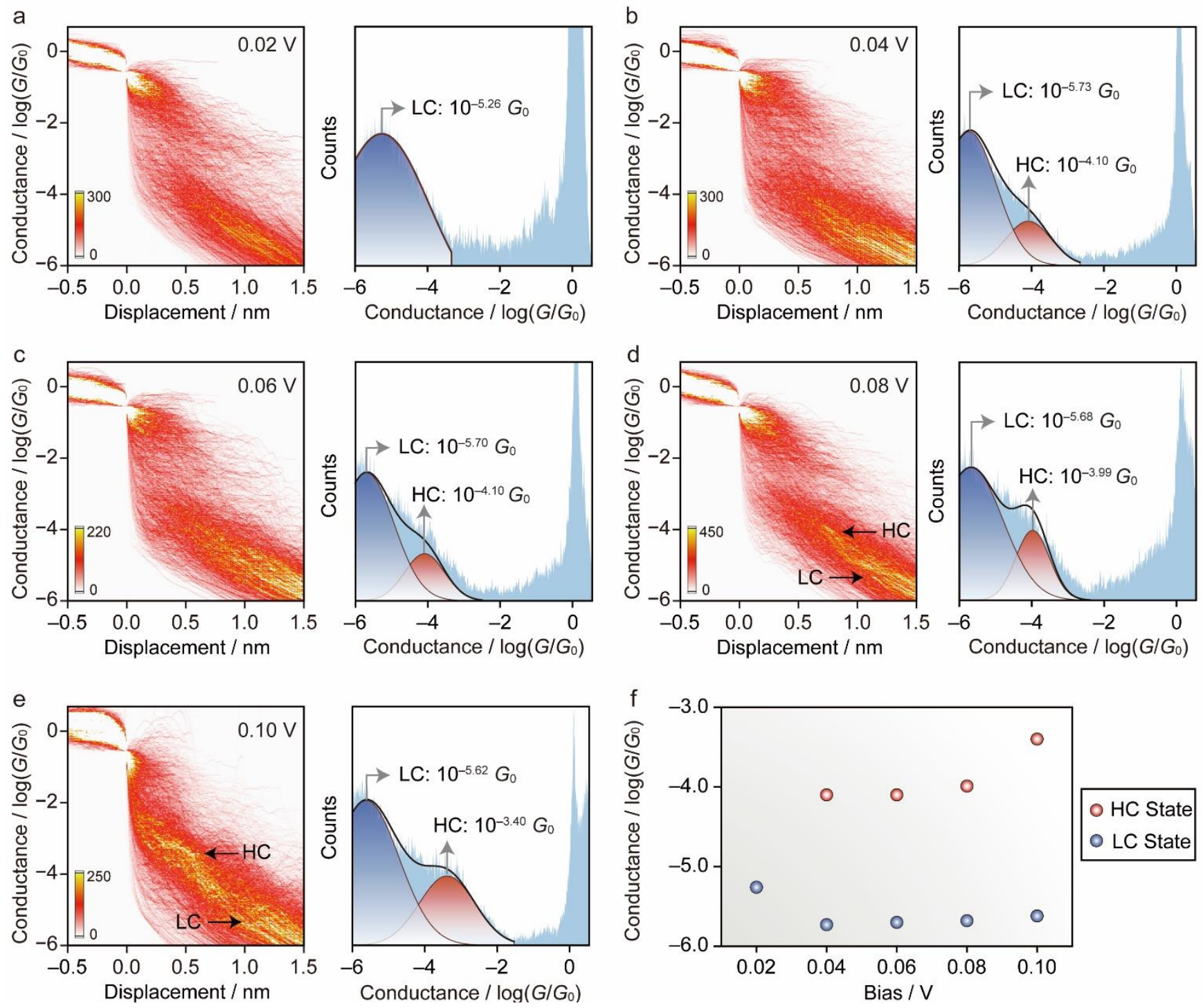

Figure S27. Bias-dependent conductance measurement of 3-DA•4PF6. (a-e) 2-D and 1-D conductance histogram measured at different bias voltages starting from (a) $20 \mathrm{mV}$, (b) $40 \mathrm{mV}$, (c) $60 \mathrm{mV}$, (d) $80 \mathrm{mV}$, to (e) $100 \mathrm{mV}$. (f) Conductances of HC and LC states as a function of bias voltages.

At $20 \mathrm{mV}$, only a LC conductance was observed at $\sim 10^{-5.26} G_{0}$. At $40 \mathrm{mV}$, a $\mathrm{HC}$ state, centered at $\sim 10^{-4.10} G_{0}$, occurred with a small portion. The portion of $\mathrm{HC}$ states increases with the increase of bias voltage (40 to $80 \mathrm{mV}$ ). At $100 \mathrm{mV}$, we can observe a clear $\mathrm{HC}$ state centered at $\sim 10^{-3.40} G_{0}$ and LC state centered at $\sim 10^{-5.62} G_{0}$. 

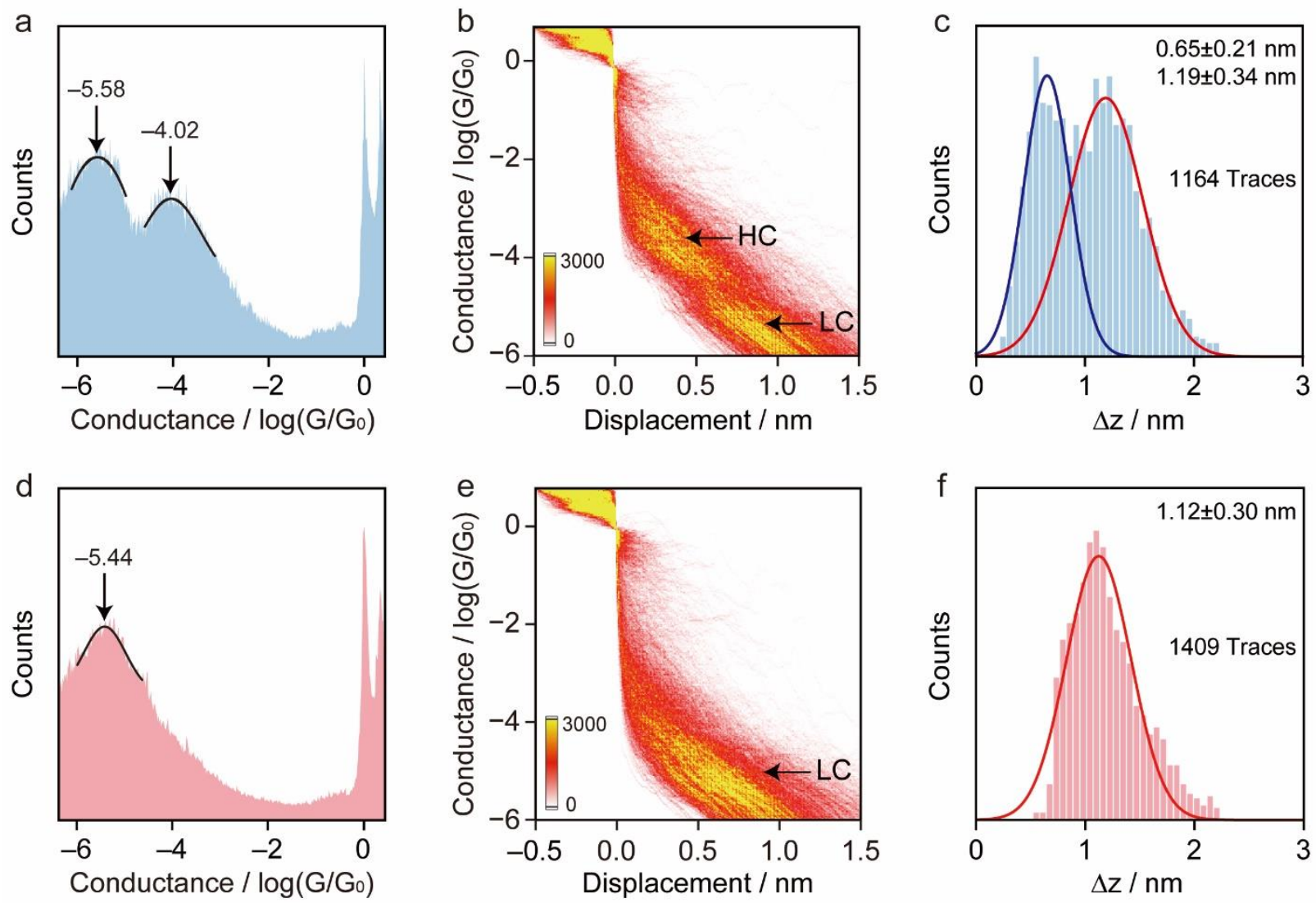

Figure S28. Using deep learning algorithm to identify the conductance characteristics of

\section{4-DA•4PF 6}

(a-c) The automatically selected 1164 traces for $4-\mathbf{D A} \bullet 4 \mathrm{PF}_{6}$ showing conductance the characteristic with a metastable $\mathrm{HC}$ state.

(a) $1 \mathrm{D}$ conductance histogram, showing a HC state of $10^{-4.02} G_{0}$ and a LC state of $10^{-5.58} G_{0}$.

(b) 2D conductance histogram showing two conductance plateaus.

(c) Relative displacement distributions of conductances-displacement traces.

(d-f) The automatically selected 1409 traces for $\mathbf{4}-\mathbf{D A} \cdot 4 \mathrm{PF}_{6}$ showing conductance the characteristic without a metastable $\mathrm{HC}$ state.

(d) $1 \mathrm{D}$ conductance histogram, showing a LC state at $10^{-5.44} G_{0}$.

(e) 2D conductance histogram showing only one conductance plateau.

(f) Relative displacement distributions of conductances-displacement traces. 


\section{Section F. Calculation Methods}

Table S2. Multiplicity analysis

\begin{tabular}{cccccc}
\hline & $\begin{array}{c}\text { Spin } \\
\text { Multiplicity }\end{array}$ & $\begin{array}{c}\text { Unpaired } \\
\text { Electrons }\end{array}$ & $\begin{array}{c}\text { Spin } \\
\text { Monmentum }\end{array}$ & $\begin{array}{c}\text { Total Energy } \\
/ \text { Hartree }\end{array}$ & $\begin{array}{c}\Delta E^{a} \\
/ \mathrm{kcal} \mathrm{mol}^{-1}\end{array}$ \\
\hline DPA* & 1 (Singlet) & 0 & 0 & -1116.046195 & -9.97 \\
& 3 (Triplet) & 2 & 1 & -1116.062078 & \\
\hline DPE* & 1 (Singlet) & 0 & 0 & -1114.896775 & \\
& 3 (Triplet) & 2 & 1 & -1114.851600 & 28.35 \\
\hline
\end{tabular}

a. The total energy difference, $\Delta E$, is defined as

$$
\Delta E=E_{\text {Triplet }}-E_{\text {Singlet }}
$$

For DPA “, the triplet form with two unpaired electrons (total spin momentum $S=1$ ) is energetically favorable, while for DPE**, the singlet $(S=0)$ has the lowest energy.

Table S3. Dipole and energy analysis under OEEF

\begin{tabular}{|c|c|c|c|c|}
\hline & $\begin{array}{c}\text { Electric Field } \\
\boldsymbol{F}_{\mathbf{z}} / \vee \mathrm{nm}^{-1} \\
\end{array}$ & $\begin{array}{c}\text { Dipole } \\
P_{z} / D \\
\end{array}$ & $\begin{array}{c}\text { Total Energy } \\
E / \text { Hartree }\end{array}$ & $\begin{array}{c}\Delta E^{a} \\
I \mathrm{kcal} \mathrm{mol}{ }^{-1}\end{array}$ \\
\hline \multirow[b]{2}{*}{ DPA $^{2+}$} & 0 & 0 & -1115.659066 & \multirow[b]{2}{*}{-2.37} \\
\hline & 2.06 & -4.77 & -1115.662838 & \\
\hline \multirow{2}{*}{ DPA“ } & 0 & 0 & -1116.062078 & \multirow[b]{2}{*}{-2.56} \\
\hline & 2.06 & -5.29 & -1116.066164 & \\
\hline \multirow{2}{*}{ DPE•• } & 0 & 0 & -1114.896775 & \multirow{2}{*}{-4.31} \\
\hline & 2.06 & -9.31 & -1114.903644 & \\
\hline \multirow{2}{*}{$\mathrm{DPE}^{2+}$} & 0 & 0 & -1114.433061 & \multirow{2}{*}{-2.87} \\
\hline & 2.06 & -6.01 & -1114.437640 & \\
\hline
\end{tabular}


a. The total energy difference, $\Delta E$, is defined as

$$
\Delta E=E\left(F_{\mathrm{z}}=2.06\right)-E\left(F_{\mathrm{z}}=0\right)
$$

It can be concluded that the OEEF could decrease the total energy for all molecular species. The DPE backbone (DPE“* and $\mathrm{DPE}^{2+}$ ) has larger induced dipoles $P_{\mathrm{z}}$ than the DPA backbone (DPA“ and $\mathrm{DPA}^{2+}$ ) and a bigger decrease in energy $|\Delta E|$, on account of the better electronic conjugation as discussed in the main text.

\section{Table S4. Transition state (TS) analysis in the dehydrogenation reaction under OEEFs}

\begin{tabular}{ccc}
\hline & $\begin{array}{c}\text { Electric Field } \\
F_{\mathbf{z}} / \mathrm{V} \mathrm{nm}^{-1}\end{array}$ & $\begin{array}{c}\text { Total Energy } \\
\boldsymbol{E} / \text { Hartree }\end{array}$ \\
\hline & 0 & -1115.961135 \\
TS & 0.51 & -1115.962287 \\
& 1.03 & -1115.964127 \\
& 1.54 & -1115.966825 \\
& 2.06 & -1115.970150 \\
\hline
\end{tabular}
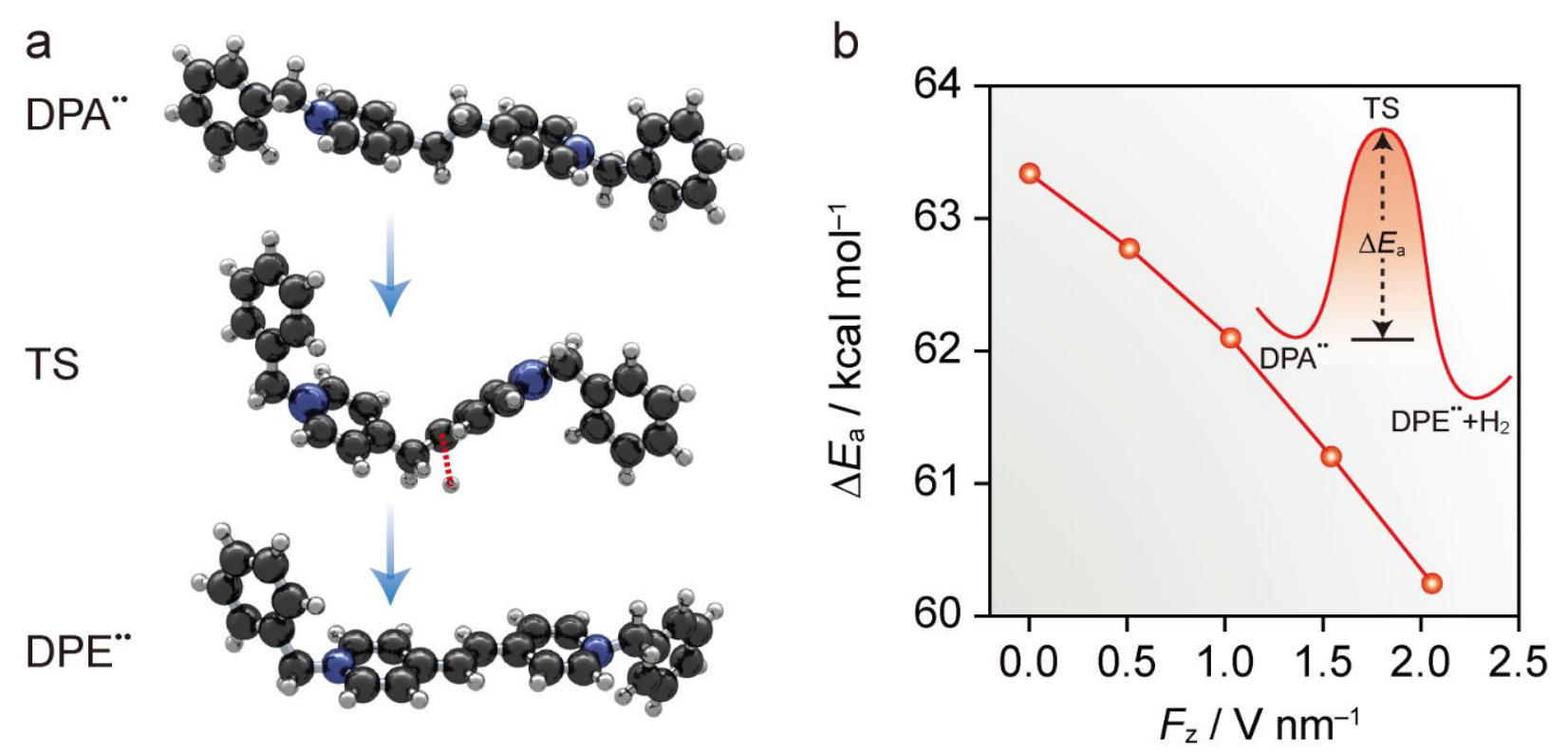

Figure S29. Kinetic activation energy barrier $\left(E_{\mathrm{a}}\right)$ of the dehydrogenation reaction under different oriented external electric fields (OEEFs). $E_{\mathrm{a}}$ is defined as: $E_{\mathrm{a}}=E(\mathrm{TS})-E\left(\mathrm{DPA}{ }^{*}\right)$. 
In the main text, we have focused on the thermodynamic energy promotion by the oriented external electric fields (OEEFs) in the dehydrogenation. The analysis of kinetic behaviour of the OEEFdependent dehydrogenation is performed (Table S4 and Figure S29) by density functional theory (DFT) calculations. According to the valence bond reactivity model ${ }^{10}$, the kinetic activation energy barrier can generally be obtained from the thermodynamic energy, combined with other effects, such as excited-state one, or a transition-state resonance effect etc. Here, we used the Gaussian package to study directly the transition state (TS) and kinetic activation barrier under different OEEFs at the first-principles level based on the DFT. Details of the calculation details can be found in the Method Section of the main text. From the Table S4 and Figure S29, we find very clearly that the kinetic activation energy barrier $\left(E_{\mathrm{a}}\right)$ of the dehydrogenation decreases with increasing OEEF, revealing that a stronger electric field results in a smaller dehydrogenation barrier. Combining these kinetic data with the thermodynamic data in the main text, we conclude that the OEEF could promote the dehydrogenation, during both the kinetic and thermodynamic stage of the process.

\section{Section G. Supplemental References}

1. Chen, H.; Zheng, H.; Hu, C.; Cai, K.; Jiao, Y.; Zhang, L.; Jiang, F.; Roy, I.; Qiu, Y.; Shen, D.; Feng, Y.; Alsubaie, F. M.; Guo, H.; Hong, W.; Stoddart, J. F. Giant Conductance Enhancement of Intramolecular Circuits through Interchannel Gating. Matter 2020, 2, 378-389.

2. Dolomanov, O. V.; Bourhis, L. J.; Gildea, R. J.; Howard, J. A. K.; Puschmann, H. OLEX2: A 
Complete Structure Solution, Refinement and Analysis Program. J. Appl. Cryst. 2009, 42, 339341.

3. Sheldrick, G. M. SHELXT-Integrated Space-Group and Crystal-Structure Determination. Acta Cryst. A 2015, 71, 3-8.

4. Sheldrick, G. M. A Short History of SHELX. Acta Cryst. A 2008, 64, 112-122.

5. Thorn, A.; Dittrich, B.; Sheldrick, G. M. Enhanced Rigid-Bond Restraints. Acta Cryst. A 2012, $68,448-451$.

6. Hong, W.; Li, H.; Liu, S.-X.; Fu, Y.; Li, J.; Kaliginedi, V.; Decurtins, S.; Wandlowski, T. Trimethylsilyl-Terminated Oligo(Phenylene Ethynylene)S: An Approach to Single-Molecule Junctions with Covalent Au-C ¿-Bonds. J. Am. Chem. Soc. 2012, 134, 19425-19431.

7. Nagahara, L. A.; Thundat, T.; Lindsay, S. M. Preparation and Characterization of STM Tips for Electrochemical Studies. Rev. Sci. Instrum. 1989, 60, 3128-3130.

8. Meszaros, G.; Li, C.; Pobelov, I.; Wandlowski, T. Current Measurements in a Wide Dynamic Range - Applications in Electrochemical Nanotechnology. Nanotechnology 2007, 18, 424004.

9. Manrique, D. Z.; Huang, C.; Baghernejad, M.; Zhao, X.; Al-Owaedi, O. A.; Sadeghi, H.; Kaliginedi, V.; Hong, W.; Gulcur, M.; Wandlowski, T.; Bryce, M. R.; Lambert, C. J. A Quantum Circuit Rule for Interference Effects in Single-Molecule Electrical Junctions. Nat. Commun. 2015, $6,6389$.

10. Shaik, S.; Shurki, A. Valence Bond Diagrams and Chemical Reactivity. Angew. Chem. Int. Ed. 1999, 38, 586-625. 